\title{
Automated Peak Width Measurements for Targeted Analysis of Ion Mobility Unresolved Species
}

\author{
Matthew R. Brantley, Michael E. Pettit, Brett Harper, Brooke Brown, Touradj Solouki \\ Department of Chemistry and Biochemistry, Baylor University, Waco, TX 76798, USA
}

*Please address reprint requests to: Professor Touradj Solouki, Department of Chemistry and Biochemistry, Baylor University Sciences Building, One Bear Place \#97348, Waco, TX 76798 Telephone number: 254-710-2678, E-mail: Touradj_Solouki@baylor.edu

(C) 2016. This manuscript version is made available under the Elsevier user license http://www.elsevier.com/open-access/userlicense/1.0/ 
Abstract (220 Words): Peak broadening in ion mobility (IM) is a relatively predictable process and abnormally broad peaks can be indicative of the presence of unresolved species. Here, we introduce a new ion mobility peak fitting (IM_FIT) software package for automated and systematic determination of traveling wave ion mobility (TWIM) unresolved species. To identify IM unresolved species, the IM_FIT software generates a trend line by plotting ions' mobility peak widths as a function of their arrival times. Utilizing user-defined thresholds, IM_FIT allows for automated and rapid detection of ions that deviate from the peak width trend line. To demonstrate the advantages of IM_FIT for automated detection of IM unresolved species, IMmass spectrometry (IM-MS) data from a sample mixture containing polypropylene glycol and multiple peptides were analyzed. A total of 14 out of the 34 observed singly-charged IM peaks above $5 \%$ relative abundance (i.e., signal-to-noise ratios above 200 ) were tagged as potentially co-eluting ions by IM_FIT. Subsequently, the 14 IM peaks tagged as potentially unresolved, presumably corresponding to co-eluting compounds, were further analyzed by automated IM deconvolution (AIMD), liquid chromatography-IM-MS (LC-IM-MS), and/or ultra-high resolution mass spectrometry. Using the aforementioned techniques, more than $85 \%$ of the tagged IM peaks (12 out of 14) were confirmed to contain co-eluting ions. As an additional new finding, IM_FIT facilitated the discovery of an unexpected sequence-scrambled y-type fragment ion.

Keywords: ion mobility spectrometry (IMS), mass spectrometry (MS), chemometrics, software, high-throughput, mixture analysis

Abbreviations: Ion Mobility (IM), Traveling Wave Ion Mobility (TWIM), Automated IM Deconvolution (AIMD), Mass Resolving Power (MRP), Collision Cross-Section (CCS), Linear Trap Quadrupole (LTQ), Sustained Off-Resonance Irradiation (SORI), Graphical User Interface 
(GUI), Polypropylene Glycol (PPG), Full Width at Half Height (FWHH), Full Width at "X\%" Height (FWXH), Arrival Time (AT), SIMPLe-to-use Interactive Self-modeling Mixture Analysis (SIMPLISMA), Selected Ion Mobility (SIM)

\section{INTRODUCTION}

Mass spectrometry (MS) is an important technique for the analysis and characterization of complex mixtures and has applications in a broad range of disciplines, such as lipidomics [1, 2], metabolomics [3], petroleomics [4, 5], and proteomics [6]. MS provides valuable analytical information by measuring the mass-to-charge $(\mathrm{m} / \mathrm{z}$ ) ratios [7] of ions in the gas phase; these $\mathrm{m} / \mathrm{z}$ values can be used to assign molecular weights and elemental compositions [8,9] as well as study molecular functional groups $[5,9,10]$. However, MS analysis of complex sample mixtures can be challenging as these sample mixtures often contain isomeric (i.e., same elemental composition but different molecular structures) and/or isobaric (i.e., different elemental composition but same nominal mass) compounds. The high mass-resolving-power (i.e., MRP defined as $\mathrm{M} / \Delta \mathrm{M}_{50 \%}$ ) of some MS instruments (e.g., Fourier transform-ion cyclotron resonance (FT-ICR) MS [11, 12] and Orbitrap [12-14] MS) is regularly used to identify isobaric compounds based only on their exact masses. Conversely, because isomeric molecules have identical masses, they cannot be differentiated by high MRP measurements of precursor molecular ions alone; other MS approaches, such as gas-phase ion-molecule reaction kinetics $[15,16]$, can be used to differentiate isomers, however, routine characterization of isomers present in complex mixtures generally requires sample pre-separation. Therefore, analyte separation techniques (e.g., high performance liquid chromatography (HPLC) [17], gas chromatography (GC) [18], ion mobility (IM) [19], etc.) are often utilized to separate isomers prior to MS analysis. 
Conventional MS-compatible separation techniques, such as HPLC [17] and GC [18], operate in the second, minute, or even hour timescales. For accelerated multidimensional analyses, IM [19] has been coupled with MS (e.g., millisecond timescale separation [20]). In HPLC and GC methods, neutral molecules are separated based on the relative affinities of molecules between stationary and mobile phases (i.e., partition coefficients) $[14,15]$. However, in IM experiments, analyte separation is achieved in the gas phase based on ions' mobilities through a (typically inert) drift gas (e.g., nitrogen $\left(\mathrm{N}_{2}\right)[20,21]$ or helium $\left.(\mathrm{He})[20,21]\right)$; ions' IM drift times are directly proportional to their collision cross-sections (CCSs) [22]. IM is compatible with many MS techniques (e.g., magnetic sector [23] MS, quadrupole [24] MS, timeof-flight (TOF) [25, 26] MS, and ion traps [27]) and has been successfully coupled with other separations techniques such as LC-IM-MS [28, 29] and GC-IM-MS [30] for enhanced multidimensional analyses.

A more recent development in IM is the introduction of traveling wave ion mobility-mass spectrometry (TWIM-MS) [22, 31]. In TWIM-MS, ions are confined radially by applying a radio frequency potential to a stacked-ring ion guide and separated by sweeping a direct current (dc) potential across the ring electrodes [31]. The dc sweep creates a "wave" which ions either "surf" on or fall over, separating ions based on their CCS differences [31]. Despite recent improvements in TWIM-MS resolving powers (i.e., as high as $\sim 240(\Omega / \Delta \Omega$ ) [32]), IM co-elution of isomeric and isobaric compounds continues to impede accurate analyte characterizations of complex mixtures such as petroleum [33] and biological [34-36] samples.

Several methodologies have been developed to characterize co-eluting compounds using existing IM-MS instrumentation (e.g., post-IM/collision induced dissociation (CID) chemometric deconvolution [37-40], mobility alignment for high- and low-energy experiments [41], energy- 
resolved IM-MS [40, 42], and monitoring post-IM generated species-specific fragment ions [43]). Although each of the aforementioned techniques can facilitate characterization of IMunresolved species (i.e., ions with similar CCSs), most approaches [37, 39-43] require isolation and subsequent fragmentation of ions at $\mathrm{m} / \mathrm{z}$ values that are suspected to correspond to multiple IM-unresolved components. Previously, we showed that plots of IM profiles' full widths at halfheights (FWHHs) vs IM arrival times (ATs) could be used to determine peak purity [44]. The original technique, however, was time consuming because FWHH and AT for each IM profile had to be manually measured and plotted, therefore reducing the method's utility for highthroughput analysis. A similar technique was later used by Jeanne Dit Fouque et al. to analyze IM-unresolved conformers of lasso peptides [45].

In this manuscript, we introduce a new automated approach for rapid analysis of peak widths for untargeted detection of IM-unresolved species in complex sample mixtures. To demonstrate the utility of IM_FIT, we analyzed a sample mixture of peptides and poly-propylene glycol (PPG) resulting in 34 singly-charged ions with observed relative abundances (RAs) above our experimental cutoff (i.e., > 5\% RA). Using IM-FIT, all IM profiles from a single mobiligram were tagged as corresponding to either single or multiple components. Validity of the tagging algorithm was confirmed by selecting IM profiles that were labeled by IM_FIT as potentially corresponding to multiple IM-unresolved components and successfully identifying these coelutions using a combination of post-IM/CID deconvolution [37, 39, 40], LC-IM-MS [17], and/or ultra-high mass resolving power MS [11, 12]. 


\section{EXPERIMENTAL}

2.1 Sample Preparation: A stock solution of polypropylene glycol containing $0.2 \mathrm{mM}$ PPG 425 and 0.2 mM PPG 1000 was purchased from Agilent Technologies (Santa Clara, CA, USA). The Gly 6 hexapeptide (amino acid sequence: GGGGGG) was purchased from SigmaAldrich (St. Louis, MO, USA). Custom synthesized hexapeptide isomers (amino acid sequences: FRMYGG and MGRYGF) were purchased from Peptide 2.0, Inc. (Chantilly, VA, USA). Optima grade acetic acid and methanol were purchased from Fisher-Scientific (Waltham, MA, USA). Water was purified (resistivity of $\sim 18.2 \mathrm{M} \Omega \bullet \mathrm{cm}$ at $25^{\circ} \mathrm{C}$; overall ionic concentration $<0.1 \mathrm{ppb}$ ) in-house, using a Direct-Q 3 UV water purification system (EMD Millipore Corp., Billerica, MA, USA). All solvents and samples were used "as is" and without any further purification or modification. A mixture containing PPG 425 and 1000, Gly ${ }_{6}$, and equimolar isomeric hexapeptides (FRMYGG and MGRYGF) was prepared and diluted in a spray solvent containing methanol (49.95\%): water (49.95\%): acetic acid $(0.1 \%)$ such that each mixture component had a final concentration of $\sim 1 \mu \mathrm{M}$.

2.2 Ion Mobility-Mass Spectrometry: All IM-MS experiments were conducted using a Synapt G2-S HDMS (Waters Corp., Milford, MA, USA) system equipped with an electrospray ionization (ESI) [22] source operated in positive-ion mode. Sample flow rate was set to $1.5 \mu \mathrm{L}$ $\min ^{-1}$ using a Standard Infusion 11 Plus syringe pump (Harvard Apparatus, Holliston, MA, USA). ESI capillary voltage was set to $3.5 \mathrm{kV}$. Source temperature was set to $100^{\circ} \mathrm{C}$. Sampling cone and source offset voltages were set to $95.0 \mathrm{~V}$ and $10.0 \mathrm{~V}$, respectively. The IM wave height and velocity were set to $40.0 \mathrm{~V}$ and $1600 \mathrm{~m} \mathrm{~s}^{-1}$, respectively. For wide mass-range experiments (viz., experiments with no $\mathrm{m} / z$-isolation event), the electric potential difference between the IM and transfer cells was kept at $2.0 \mathrm{~V}$. To avoid and minimize pre-IM/CID, the electric potential 
difference between the exit of the trap cell and the entrance of the helium cell (i.e., trap collisionenergy) was kept at $4.0 \mathrm{~V}$ for all experiments. Argon (Ar) gas pressure readouts for the trap and transfer cells were $\sim 2.0 \times 10^{-5}$ bar, and $\sim 2.2 \times 10^{-5}$ bar, respectively. Nitrogen $\left(\mathrm{N}_{2}\right)$ gas pressure readouts for the IM cell was $\sim 2.1 \times 10^{-2}$. Helium $(\mathrm{He})$ gas pressure readout for the helium cell (used for collisional cooling prior to entrance to the IM cell [22]) was $~ 1.4$ bar. All reported gas pressures were from direct instrument readouts and have not been corrected for chemical sensitivity or geometry factors [46-48]. For post-IM/CID MS experiments, the precursor ions of interest (e.g., singly-protonated hexapeptide isomers, $\left[\mathrm{M}_{\mathrm{hex}}+\mathrm{H}\right]^{+}$at $m / z$. 730.3, Figure $2 \mathrm{~d}$ ) were $m / z$-isolated in the quadrupole mass filter prior to IM separation. Post-IM/CID was achieved by setting a $35 \mathrm{~V}$ (for $\mathrm{m} / \mathrm{z} 598.3$ ), $40 \mathrm{~V}$ (for $\mathrm{m} / \mathrm{z}^{\prime} \mathrm{s} 542.3,599.3$, and 600.3), or $50 \mathrm{~V}$ (for $\mathrm{m} / \mathrm{z} 730.3$ ) potential difference between the exit of the IM cell and entrance of the transfer cell. The instrument "scan" time was set to 1 second. To obtain signal-to-noise ratios of $>200$ for all ions of interest, all IM-MS data reported herein were acquired and averaged for 3 minutes.

2.3 Liquid Chromatography-Mass Spectrometry: The purity of the MGRYGF hexapeptide was tested via LC-IM-MS using a nanoACQUITY ultra performance liquid chromatograph (UPLC) (Waters Corp., Milford, MA, USA) operated in gradient mode (solvent A was $\mathrm{H}_{2} \mathrm{O}$ with $0.1 \%$ formic acid and solvent $\mathrm{B}$ was acetonitrile with $0.1 \%$ formic acid) connected to a Synapt G2-S HDMS system. A 30 minute linear gradient of 5\% B to 60\% B was used for analyte separations prior ionization and subsequent IM-TOF MS analyses. Source conditions were optimized for production and transmission of $\left[\mathrm{M}_{\mathrm{hex}}+\mathrm{H}\right]^{+}$at $m / z, 730.3$ (i.e., soft conditions) in which the capillary voltage was kept at $2.0 \mathrm{kV}$ and both the sampling cone and source offset voltages were set to $10 \mathrm{~V}$. 
2.4 Fourier Transform-Ion Cyclotron Resonance Mass Spectrometry: Mass spectra for all ultra-high mass resolving power (i.e., $\mathrm{M} / \Delta \mathrm{M}_{50 \%} \approx 120,000$ at $\mathrm{m} / 2$ 600) experiments were acquired using an FT-ICR mass spectrometer equipped with a cylindrical penning trap (formerly IonSpec Corp., now owned by Agilent Technologies, Inc., Santa Clara, CA, USA) and a 9.4 tesla superconducting magnet (Cryomagnetics, Inc., Oak Ridge, TN, USA). Ions were generated externally using ESI (flow rate of $\sim 5 \mu \mathrm{L} \mathrm{min}^{-1}$ ) operated in positive-ion mode (capillary voltage of $3.5 \mathrm{kV}$ ). Ions generated during ESI were transferred via a quadrupole ion guide to a hexapole accumulation cell [47]. After 4 seconds of accumulation, trapped ions were transferred from the accumulation hexapole to the ICR cell via a transfer hexapole. Source temperature was set to $150^{\circ} \mathrm{C}$. Sampling cone and extractor cone voltages were set at $40.0 \mathrm{~V}$ and $10.0 \mathrm{~V}$, respectively. Ion accumulation hexapoles and ion-guide quadrupoles and hexapoles were set to "rf-only" wide-mass storage and transport modes. To fragment the singly-charged FRMYGG and MGRYGF peptides (i.e., [FRMYGG $+\mathrm{H}]^{+}$and $[\mathrm{MGRYGF}+\mathrm{H}]^{+}$at $\mathrm{m} / z$ 730.3341), sustained off-resonance irradiation (SORI)-CID [49] with a frequency offset of $+1000 \mathrm{~Hz}$ (using $\mathrm{N}_{2}$ as the collision gas reagent) was utilized.

2.5 Orbitrap Mass Spectrometry: Orbitrap mass spectra were collected using a linear trap quadrupole (LTQ)-Orbitrap Discovery mass spectrometer (Thermo Fisher Scientific, Waltham, MA, USA) equipped with an ESI source operated in positive-ion mode. The mass resolving power $\left(\mathrm{M} / \Delta \mathrm{M}_{50 \%}\right)$ of the Orbitrap was set to the highest available setting (i.e., $\sim 30,000$ at $\mathrm{m} / \mathrm{z}$ 400). Source, tube lens, and capillary voltages were set to $3.0 \mathrm{kV}, 4.8 \mathrm{~V}$ and $5.0 \mathrm{~V}$, respectively. Capillary temperature was set at $350{ }^{\circ} \mathrm{C}$. Auxiliary and sheath gasses were set at 40 and $60 \mathrm{AU}$, respectively. Isolation and CID were performed using the LTQ at a normalized collision energies of $35 \mathrm{~V}(\mathrm{~m} / z 542.3)$ or $30 \mathrm{~V}$ (all other $m / z^{\prime} \mathrm{s}$ ). Sample injection rate was set at $5.0 \mu \mathrm{L} \mathrm{min}^{-1}$ and 
each spectra was generated as the average of 20 scans (or a sample acquisition time of $\sim 17$ seconds at a scan rate of $\sim 70 \mathrm{scans} / \mathrm{min})$.

2.6 Data Analysis: Raw IM-MS and LC-IM-MS data were analyzed using MassLynx software version 4.1 (Waters Corporation, Milford, MA, USA). FT-ICR MS data were analyzed using Omega software (previously IonSpec Corp., now a part of Agilent Technologies, Santa Clara, CA). Theoretical $\mathrm{m} / \mathrm{z}$ values were generated using Exact Mass Calculator (previously IonSpec Corp., now a part of Agilent Technologies, Santa Clara, CA) using a theoretical mass resolving power of $120,000\left(\mathrm{M} / \Delta \mathrm{M}_{50 \%}\right)$ to emulate experimental resolving powers. Orbitrap mass spectra were analyzed using the Xcalibur software, version 2.2 SP1.48 (Thermo Fisher Scientific, Waltham, MA, USA). Data preprocessing and automated IM deconvolution (AIMD) analysis (including the optimization of AIMD offset values) were performed as previously described in detail [39]. All AIMD deconvoluted mass spectra were determined to match reference mass spectra with $R$ values $>0.75$ [40]. The IM_FIT graphical user interface (GUI) was developed and integrated into Matlab R2015a (The MathWorks, Inc., Natick, MA, USA) and has been tested to function in versions as old as R2008a. An MS intensity threshold of 5\% RA (equivalent to signal-to-noise ratio 200 in our experiments) was used for all IM_FIT analyses discussed in here.

\section{RESULTS AND DISCUSSION}

3.1 IM_FIT Graphical User Interface: Prior to IM_FIT analysis, IM-MS data were imported into Matlab and compiled into a 2-dimensional array using our previously reported preprocessing algorithm [39]. Figure 1 shows a screen capture of the IM_FIT graphical user interface (GUI) during analysis of 2-dimensional IM-MS data from a sample containing isomeric 
hexapeptides FRMYGG and MGRYGF, Gly 6 , and PPG species. All functionalities of the IM_FIT software are controlled within the custom designed GUI (Fig. 1). The desired data set for analysis, as well as the desired fitting method (i.e., raw (non-fitted) data, Gaussian fitted, or cubic spline interpolated; discussed in detail in the following paragraph) can be selected using the two drop down boxes in the upper right hand corner of Fig. 1 (labeled as "(a)").

The IM_FIT software is capable of measuring IM peak widths using three different methods: "raw data", "cubic spline interpolated", and "Gaussian fitted". A "raw data" peak width measurement first defines IM peak height as the peak's global maxima (i.e., the highest intensity point) and then measures IM peak width at a user defined percentage of that height (e.g., 50\% peak height). "Raw data" peak width measurement is included in the software to emulate manual measurement of peak widths for comparison purposes. "Gaussian fitted" first fits the mobility data to a Gaussian distribution, such as previously reported [44], and returns two values, $\mu$ (i.e., peak centroid or AT) and $\sigma$ (i.e., standard deviation), where $\sigma$ is subsequently used to calculate the FWHH using equation 1 [50]:

(Eq. 1)

$$
F W H H=2 \sigma \sqrt{2 \ln (2)}
$$

"Cubic spline interpolated" first fits a cubic spline (i.e., a third order polynomial) [51] between each consecutive point in the mobiligram and then defines peak height as the fitted peak maxima. Peak width is then measured at a user defined percentage (i.e., full width at "X\%" height $(\mathrm{FWXH}))$ of the "cubic spline interpolated" peak height.

The four boxes in the panel denoted under "(b)" in Fig. 1 allow for selection of IM_FIT analysis parameters. The first parameter labeled "Use Averaging" enables and disables the use of peak averaging in FWXH calculations. When averaging is disabled, only the mobiligram 
corresponding to the highest $\mathrm{m} / \mathrm{z}$ value (for a particular mass spectral peak) is used for peak width measurements. However, when averaging is enabled, mobiligrams for all $\mathrm{m} / \mathrm{z}$ values representing a continuous mass spectral peak (above the user defined "Minimum RA") are averaged to produce a single mobiligram prior to peak width measurements. The "Measurement Height" parameter defines the percentage of peak heights that peak widths will be measured. Once a data set has been selected and analysis parameters have been chosen, the RUN button (Fig. 1c) can be used to initialize the peak width analysis process.

Another option included with IM_FIT GUI is the ability to remove multiply-charged species from the dataset prior to IM_FIT analysis. It has been previously shown that arrival times in both drift tube IM-MS [52] and TWIM-MS [53] can be leveraged to determine ion charge states. As expected, re-plotting the extensive experimental CCS measurements by Valentine et al. [54] (Supplemental Figure S1) to represent CCS as a function of $m / z$ for singly- and doublycharged ions shows that, for a given $\mathrm{m} / \mathrm{z}$, CCS values for singly- and doubly-charged species differ. For example, using polynomial fits (supplemental Fig. S1) of the mobility-mass correlation [55] for each charge state, the predicted CCSs for a singly- and doubly-charged ion at $m / z 400$ are $129 \AA^{2}$ and $213 \AA^{2}$, respectively (a 66\% difference). Likewise, for a singly-charged ion at $m / z 900$ the predicted CCS is $222 \AA^{2}$ whereas the predicted CCS for a doubly-charged ion at $m / z 900$ is $353 \AA^{2}$ (a 59\% difference).

Expected IM arrival time differences can be leveraged to predict ions' charge states based solely on ions' ATs and $m / z$ 's. For all detected ions, IM_FIT calculates an average ratio of massto-charge over arrival time and then removes all peaks with arrival time values greater than a predefined percentage of deviation. For experiments discussed here, an arrival time deviation of $20 \%$ (from the interpolated AT values) was utilized which resulted in $100 \%$ positive 
identification of multiply- and singly-charged ions when manually verified. It should be noted that this feature requires a predominately singly-charged spectral data set (for proper singlycharged trend predications), thus it can be turned off (default state is on) by deselecting the toggle button labeled "Remove Multiply-Charged Species". A detailed discussion regarding the removal of multiply-charged species prior to IM_FIT analysis is offered in the supplemental section (viz. Supplemental Equations 1-3).

The IM_FIT GUI utilizes a multi-function display window (shown in section "(d)" of Fig. 1). In its default state, this window shows a plot containing each analyzed IM peak's width as a function of AT. However, this window can also be toggled to display fitted (i.e., Gaussian or cubic spline interpolated) mobiligrams for visual inspection of peak fitting results. Controls for zooming in, zooming out, and panning of the display window (section "(e)" in Fig. 1) function the same for both the FWXH vs AT as well as mobiligram views. The numerical information (i.e., data table of AT, $m / z$, FWXH, and Mobiligram "Sum" values in section "(f)" of Fig. 1) generated during the IM_FIT analysis can be copied and pasted into user selected spreadsheet software. Sorting parameters for the numerical information can be changed using the drop down box labeled "Sort By:" (section “(g)" in Fig. 1). Selection of individual fitted mobiligrams for visual analysis in the display window is accomplished by selecting an $\mathrm{m} / \mathrm{z}$ value of interest in the data table and pressing the button labeled "Spectra" (section (g) in Fig. 1); multiple mobiligrams can be overlaid by toggling the "Hold" button. When the "Hold" button is enabled, mobiligrams corresponding to the selected $\mathrm{m} / \mathrm{z}$ values can be overlaid on the same plot. The analyst can return to the FWXH vs AT view at any time by pressing the "Spectra" button again, which is re-labeled "Return" when viewing individual (or overlaid) mobiligrams. 
IM_FIT generates three non-linear regressions ("trend line", "warning line", and "action line") which are displayed as three overlaid lines on the scatter plot shown in Fig. 1 (labeled "(d)"). The bottom line (blue line with the lowest peak width values and referred to as the "trend line"), was generated using the convex hull function in Matlab 2015a (convex hull vector-set was reduced to represent only lower extrema). Please note that the term "trend line" is used but does not imply that the trend is necessarily a linear relationship. Previous approaches $[44,45]$ have utilized a least-mean-squares linear regression for predicting FWHH at given ATs. Although linear regressions may be acceptable approximations over short mobility windows, peak broadening in IM-MS is primarily governed by ion diffusion and is non-linear in relationship to peak width and AT [56]. The "warning" and "action" lines in Fig. 1 were calculated by shifting the trend line points upwards along the y-axis (i.e., peak width) using user defined percentages; here, shift percentages of $10 \%$ and $20 \%$ were used for the warning and action lines, respectively. Ions' locations relative to these lines are noted in the $\mathrm{Z}$ column (labeled "(f)" in Fig. 1), where $\mathrm{Z}$ $=0$ denotes that an ion is below the warning threshold and represents the lowest probability of co-elution, $\mathrm{Z}=1$ denotes that an ion is above the warning threshold but below the action threshold indicating an increased probability of co-elution, and $\mathrm{Z}=2$ denotes that an ion is above the action threshold indicating a high-probability of co-elution. These limits (and in turn the subsequent $\mathrm{Z}$ assignments) can be adjusted in the options panel to meet the requirements of individual analysis.

3.2 Gaussian and Cubic Spline Interpolation Peak Fitting Approaches: The factorydefined data acquisition parameters for the Synapt G2-S yield 200 TOF pushes per total IM separation time, thus extracted IM profiles for individual $\mathrm{m} / \mathrm{z}$ values (i.e., selected IM (SIM) profiles) may be defined by as few as $\sim 7$ data points across each peak (Fig. 2a, open squares). 
Because the acquired IM data is digitized at a relatively low rate (i.e., 200 TOF pushes per IM separation of $\sim 14 \mathrm{~ms}$ (data points at $\sim 70 \mu$ s intervals)), mobility peak data can be insufficient for accurate identification of true IM peak maxima. For example, unless an instrument measurement event occurs exactly at the maxima of a particular IM profile, the recorded peak maxima will not be representative of the true maxima for the traveling ion population and thus the recorded AT maxima would be skewed.

Figure 2 shows examples of four major fitting scenarios (from the experiments discussed herein) for near-"ideal" IM data (Fig. 2a, a "single" distribution, or closely related population of conformations, where one of the sampling events coincides almost exactly with the arrival time maxima), heavily distorted IM data (Fig. 2b, where sampling points are away from the true peak maxima), partially unresolved overlapping IM data (Fig. 2c, where two or more ion populations are partially co-eluting), and unresolved overlapping IM data (Fig. 2d). In each example, the raw data is plotted as open squares, a Gaussian fit of the raw data is plotted as a dashed line, and a cubic spline interpolation is plotted as a solid line.

Fig. 2a shows the mobiligram for experimental $\mathrm{m} / \mathrm{z}$ 399.1, corresponding to $\left[\mathrm{Gly}_{6}+\mathrm{K}\right]^{+}$ (theoretical $\mathrm{m} / \mathrm{z}$ 399.1). Ionized Gly 6 potassium adduct $\left(\left[\mathrm{Gly}_{6}+\mathrm{K}\right]^{+}\right)$is presumed to behave similarly in the gas-phase to $\left[\mathrm{Gly}_{6}+\mathrm{H}\right]^{+}$which has a self-solvated globule conformation [57] resulting in a single elution peak and hence was selected as a control for a "pure" IM peak. Calculating the arrival time for $\mathrm{m} / \mathrm{z} 399.1$ using the typical method of taking the highest intensity data point (i.e., raw data peak maxima, viz., open squares in Fig. 2a) yielded an AT of $2.493 \mathrm{~ms}$. Calculating arrival time based on the Gaussian fit's mean (i.e., the normal distribution's $\mu$, viz., dashed line in Fig. 2a) and cubic spline interpolation (viz., solid line in Fig. 2a) resulted in ATs of $2.486 \mathrm{~ms}$ and $2.489 \mathrm{~ms}$, respectively. The raw data shown in Fig. 2a exemplifies a near "ideal" 
scenario for IM data and arrival time determination, as (i) the IM profile in Fig. 2a corresponds to a "single" known conformation correlating strongly with the single-component PPG trend line in Fig. 3 as discussed below and (ii) one of the sampled or digitized points (viz., point at $\mathrm{AT}=$ $2.493 \mathrm{~ms}$ ) coincides with peak maxima; therefore, both the Gaussian and cubic spline interpolation ATs are in close agreement with raw data peak maxima ( $\triangle \mathrm{ATs}$ of $0.007 \mathrm{~ms}$ and $0.004 \mathrm{~ms}$, respectively).

Fig. $2 \mathrm{~b}$ shows the mobiligram for experimental $\mathrm{m} / \mathrm{z} 407.2$, corresponding to the $\left[\mathrm{a}_{3}\right]^{+}$ fragment of FRMYGG (all fragment ions are labeled using Roepstorff and Fohlman's nomenclature [58]). Because ATs calculated from unmodified raw data are subject to potential errors resulting from low digitization rates, it is not surprising that ATs of the Gaussian (3.159 $\mathrm{ms})$ and cubic spline interpolated $(3.155 \mathrm{~ms})$ data differ from the peak maxima AT of the raw data $(3.186 \mathrm{~ms})$ to yield $\Delta$ ATs of $0.027 \mathrm{~ms}$ and $0.031 \mathrm{~ms}$ for the Gaussian and cubic spline interpolation, respectively. Arrival times from the fitted data (i.e., Gaussian and cubic spline interpolated) are in close agreement with each other (i.e., $\Delta \mathrm{AT}$ of $0.004 \mathrm{~ms}$ ). Thus, the data shown in Fig. $2 b$ exhibit the impact of detrimental peak distortion in digitized data on accurate AT determination (i.e., the theoretical peak maxima falls between two measurement events) and demonstrate a scenario where peak fitting is advantageous.

Fig. 2c shows the mobiligram for experimental $\mathrm{m} / \mathrm{z} 570.3$, corresponding to the $\left[\mathrm{a}_{4}\right]^{+}$ fragment of FRMYGG, where raw data is plotted as open squares, a Gaussian fit of the raw data is plotted as dashed line, and a cubic spline interpolation is fitted as solid line. The AT for $\mathrm{m} / \mathrm{z}$ 570.3 from the raw data (i.e., using highest intensity sampled raw data point) was $4.432 \mathrm{~ms}$. In comparison to the raw data fitting method, ATs calculated using the Gaussian fit (4.454 ms) and cubic spline fit (4.448 ms) had $\Delta$ ATs of $0.022 \mathrm{~ms}$ and $0.016 \mathrm{~ms}$, respectively. The system shown 
in Fig. 2c exemplifies a scenario where Gaussian fitting returns a peak shape markedly different from cubic spline interpolation. The raw data mobiligram for $\mathrm{m} / \mathrm{z} 570.3$ (open squares, Fig. 2c) exhibits a partially-resolved shoulder at the later AT (of $\sim 4.8 \mathrm{~ms}$ ) with a (y-scale) normalized peak intensity lower than the selected width measurement threshold (i.e., 50\% maxima). However, due to the rigid unimodality of a Gaussian distribution, the best fit (i.e., that with the lowest least-mean-squared error) is a poor representation of the experimental peak characteristics that are clearly polymodal. In both fitting methods, the FWHH vs AT ratios deviate significantly from the trend line shown in Fig. 3 (discussed below).

Similar to the mobiligrams shown in Fig. 2a and Fig. 2b, the IM peak shown in Fig. 2d exhibits a single Gaussian-like distribution that would most likely be interpreted as corresponding to a single component. Akin to the results in Fig. 2b, AT calculations for the Gaussian fit (5.413 ms) and cubic spline interpolation (5.410 ms) of $\mathrm{m} / \mathrm{z} 730.3$ (Fig. 2d) were in agreement $(\Delta \mathrm{AT}=0.003 \mathrm{~ms})$ but were also, unlike Fig. $2 \mathrm{~b}$, close to the raw data arrival time of $5.402 \mathrm{~ms}(\Delta \mathrm{ATs}$ of 0.011 and $0.008 \mathrm{~ms}$ in relation to Gaussian fit and cubic spline interpolated values, respectively). However, upon IM peak width analysis of $\mathrm{m} / \mathrm{z} 730.3$, a significant deviation (> 20\%) from the PPG trend line was observed (shown as an open star in Fig. 3, at an AT of $\sim 5.4 \mathrm{~ms}$ ). This deviation was expected, as the mobility information shown in Fig. $2 \mathrm{~d}$ is actually representative of two IM-unresolved isomeric components (i.e., $\left[\mathrm{M}_{\mathrm{hex}}+\mathrm{H}\right]^{+}$of FRMYGG and $\left[\mathrm{M}_{\mathrm{hex}}+\mathrm{H}\right]^{+}$of MGRYGF (both at $\mathrm{m} / z$ 730.3)). Therefore, without some form of further data analysis (such as peak width analysis or fragment ion analysis [43]) the SIM profile of the isomeric hexapeptides in Fig. $2 \mathrm{~d}$ would not be assigned as containing multiple conformations. 
Additional details on the SIM profiles shown in Fig. 2, including peak widths and multitrial statistics, are shown in Table 1. Based on the aforementioned discussions, it was concluded that cubic spline interpolation is favorable when peak shapes are "leaning", partially resolved, or otherwise non-Gaussian. Outside of these cases, Gaussian fits are preferred as the peak shape is indicative of real physical phenomena [56] and, in many cases, produced more reliable fits for peaks defined by relatively few data points (i.e., < 4). In general, both peak fitting methods yielded more accurate AT determinations than raw data alone. Because IM peak shapes from the experiments discussed within this manuscript were Gaussian-shaped and contained relatively few partially unresolved ions, all reported results were generated using a Gaussian fit measured at $50 \%$ height.

3.3 FWHH vs AT Analysis: Figure 3 shows the FWHH vs AT plot for a mixture of PPG, two isomeric hexapeptides (amino acid sequences: FRMYGG and MGRYGF), and Gly6. Isotopic peaks were removed to reduce pictorial complexity in Figure 3, however a complete list of all identified singly-charged ions (including isotopes) and their associated ATs, $\mathrm{m} / \mathrm{z}$ values, FWHHs, $\mathrm{Z}$ values, and fragment assignments are presented in Table 1. SIM profiles were fit to a Gaussian distribution in IM_FIT as explained above (Fig. 2) and multiply-charged species were removed automatically by IM_FIT (see experimental section).

The intended purpose of IM_FIT was to probe complex mixtures for IM-unresolved species (e.g., isomers/conformers with similar CCSs); therefore, it was necessary to reduce the error associated with the FWHH vs AT plot as much as possible. For example, if the measurement error associated with the peak widths used for the single-component trend line were larger than the peak broadening resulting from two (or more) IM-unresolved species, then the unresolved species would fall on the single-conformer trend line and be undetectable by 
IM_FIT. However, if the peak broadening due to unresolved components were greater than the peak width measurement error of the single component trend line, the peak would deviate from the single component FWHH vs AT trend line and be identifiable by IM_FIT. Therefore, the farther an ion's SIM peak width deviates from the single-conformer trend line, the more confidently it can be tagged as corresponding to multiple IM-unresolved species (i.e., coelution).

Solid triangles in Fig. 3 correspond to repeating sodiated-PPG subunits (i.e., [(PPG $)_{\mathrm{n}}+$ $\mathrm{Na}]^{+}$), where " $\mathrm{n}$ " corresponds to the number of repeating subunits (denoted numerically from 5 to 15 beneath each solid triangle). Repeating sodiated-PPG subunits were chosen as an internal calibration as they were assumed to have discrete "single-conformer" IM distributions and followed a predictable trend when plotting FWHH vs AT, as previously reported [44, 61]. In addition, these ions covered a wide range of arrival times (i.e., $\sim 2$ to $8 \mathrm{~ms}$ ) under our experimental conditions. $\left[(\mathrm{PPG})_{6}+\mathrm{Na}\right]^{+},\left[(\mathrm{PPG})_{7}+\mathrm{Na}\right]^{+}$, and $\left[(\mathrm{PPG})_{8}+\mathrm{Na}\right]^{+}$in the mixed samples yielded slightly wider peak widths that did not follow the general trend exhibited by the other PPG subunits. Visual assessment of unfitted (i.e., raw data) IM peak shapes for these ions show Gaussian-like distributions (data not shown). However, IM_FIT analysis revealed that their mobility distributions were asymmetric and leaning towards the earlier ATs. In separate experiments, when pure PPG sample mixture was ran individually, peak widths for all PPG subunits measured by IM_FIT followed a more uniform trend [61] (Supplemental Figure S2), indicating potential co-elution with other unidentified sample constituents in the complex mixture.

The $[\mathrm{M}+1]^{+}$isotopes (i.e., $\left.{ }^{13} \mathrm{C}_{1},{ }^{2} \mathrm{H}_{1},{ }^{17} \mathrm{O}_{1}\right)$ of $\left[(\mathrm{PPG})_{6}+\mathrm{Na}\right]^{+},\left[(\mathrm{PPG})_{7}+\mathrm{Na}\right]^{+}$, and $\left[(\mathrm{PPG})_{8}+\mathrm{Na}\right]^{+}$are also included in Table 1 as their intensities are above the pre-defined $5 \%$ 
relative abundance cutoff and have peak widths much closer to the extrapolated trend line (and in agreement with the PPG-only results in supplemental Fig. S2). Because IM_FIT generates a trend-line based on the lowest FWHH values at a given AT (discussed above), the $[\mathrm{M}+1]^{+}$ isotopes of $\left[(\mathrm{PPG})_{6}+\mathrm{Na}\right]^{+}$and $\left[(\mathrm{PPG})_{8}+\mathrm{Na}\right]^{+}$were selected by IM_FIT for defining a portion (2.77 to $3.58 \mathrm{~ms}$ ATs) of the trend line. A trend of decreasing peak widths for the isotopes of species deviating from the single component trend line was observed. This isotope-dependent broadening trend was unexpected and could be attributed to potential non-linear response of the MS detector, nonlinear noise contributions at low ion abundance levels, or concentration dependent broadening processes. Although it is beyond the scope of presented work, in future, we plan to study the importance of noise level contributions and potential concentration dependent broadening for very low ion abundance species (e.g., s/n $<5$ ). In total, fourteen peaks were identified as potential co-elution by IM_FIT. Of the fourteen peaks tagged, nine were identified as corresponding to ions generated from the hexapeptides FRMYGG and MGRYGF and the remaining five were generated from PPG (details are discussed in the following sections).

\subsection{Post-IM/CID Deconvolution Analysis of Suspected Multiple Conformers:}

Verification of multiple IM-unresolved components for some $m / z$ values tagged by IM_FIT (i.e., those deviating from the trend line in Fig. 3) was accomplished using post-IM/CID combined with automated ion mobility deconvolution (AIMD). [37, 39, 40] Briefly, AIMD utilizes SIMPLe-to-use Interactive Self-modeling Mixture Analysis (SIMPLISMA) [62] to assign postIM/CID generated fragment ions to IM-convoluted precursor ions (based on slight differences in their IM ATs) and reconstructs CID mass spectra and IM-profiles for each component. [37, 39, 40] Ion mobility profiles for a total of five species (for $m / z$ values of $542.3,598.3,599.3,600.3$, 
and 730.3) that deviated from the single-conformer trend line in Fig. 3 were successfully deconvoluted using AIMD (shown in Figure 4); deconvolution of each ion population resulted in identification of two distinct components with Gaussian-like IM distributions (Figure 4a-e). AIMD analysis does not incorporate any population fitting requirements [39], thus any Gaussian shaped distribution is purely empirical (not the result of any data fitting or manipulation) and is an additional independent indication of an accurate deconvolution. Post-IM/CID of the PPG species resulted in complete signal loss for the $\left[(\mathrm{PPG})_{\mathrm{n}}+\mathrm{Na}\right]^{+}$and $\left[(\mathrm{PPG})_{\mathrm{n}}+\mathrm{K}\right]^{+}$ions without any detectable fragment generation. We suspect that ion losses were due to the loss of the $\mathrm{Na}^{+}$or $\mathrm{K}^{+}$cations (upon CID) as reported in the literature [63], and therefore deconvolution was not possible for these ions.

Deconvoluted profiles for the $\left[\mathrm{M}_{\text {hex }}+\mathrm{H}\right]^{+}$ions from the isomeric FRMYGG and MGRYGF peptides (m/z 730.3, Fig. 4a) showed two distinct Gaussian-shaped populations with the earlier arriving component (dotted line) corresponding to FRMYGG with an AT of $5.263 \mathrm{~ms}$ and the later arriving component (solid line) corresponding to MGRYGF with an AT of 5.332 ms. Deconvolution of $\left[\mathrm{M}_{\mathrm{hex}}+\mathrm{H}\right]^{+}$yielded correct hexapeptide elution order and IM ATs as confirmed by measuring isomerically pure forms of the hexapeptides under the same experimental conditions. In addition to the isomeric hexapeptides (that were expected to fall off the single-component trend line in Fig. 3) ions at $\mathrm{m} / \mathrm{z}$ 598.3, 599.3, 600.3, and 601.3 (corresponding to the $\left[\mathrm{b}_{4}\right]^{+}$from FRMYGG, $\left[\mathrm{y}_{5}\right]^{+}$from MGRYGF, $\left[\mathrm{y}_{5}+\mathrm{NH}_{3}\right]^{+}$from FRMYGG, and their convoluted isotopes, respectively) also fell off the single-component trend line, suggesting that these IM peaks corresponded to more than one component and/or conformer. AIMD deconvolution of $m / z 598.3,599.3$, and 600.3 (Fig. 4b-d) showed that IM peaks for these species contained two distinct IM-unresolved populations for each $\mathrm{m} / \mathrm{z}$ and validated the utility 
of the automated peak width analysis. Moreover, comparison of the theoretical and experimental relative abundance for the first isotope $\left({ }^{13} \mathrm{C}_{1}\right)$ of $\left[\mathrm{y}_{5}\right]^{+}(\mathrm{m} / \mathrm{z}$ 600.3) from MGRYGF (Supplemental Figure S3) suggested that the peak at $\mathrm{m} / \mathrm{z}, 600.3$ must come from at least two components (i.e., first isotope of $\left[\mathrm{y}_{5}\right]^{+}$from MGRYGF and another ion at the same nominal mass). Summation of the theoretical relative abundances for the independent isotopic envelopes of $\left[\mathrm{b}_{4}\right]^{+}$and $\left[\mathrm{y}_{5}+\mathrm{NH}_{3}\right]^{+}$from FRMYGG and $\left[\mathrm{y}_{5}\right]^{+}$from MGRYGF yields a total isotopic envelope which matched closely with the experimentally observed relative abundances at $\mathrm{m} / \mathrm{z}$ 598.3, 599.3, 600.3, and 601.3 (supplemental Fig. S3). Based on these theoretical calculations, it was expected that with sufficient mass resolving power, at least two species should be detectable for $m / z$ 599.3. To test this hypothesis, we performed additional experiments using FT-ICR MS. FT-ICR mass spectra (Supplemental Figure S4) showed two distinct peaks at $\mathrm{m} / \mathrm{z} 599.2843$ (isotope of $\left[\mathrm{b}_{4}\right]^{+}$from FRMYGG at theoretical $\mathrm{m} / \mathrm{z}$ 599.2840; $0.50 \mathrm{ppm}$ error) and $\mathrm{m} / \mathrm{z} 599.2931$ $\left(\left[\mathrm{y}_{5}\right]^{+}\right.$from MGRYGF at theoretical $\mathrm{m} / \mathrm{z}$ 599.2936; $0.83 \mathrm{ppm}$ error), supporting our previously discussed fragment ion assignments (supplemental Fig. S3). However, the $\left[\mathrm{y}_{5}+\mathrm{NH}_{3}\right]^{+}$fragment ion from FRMYGG was not observed under the FT-ICR MS experimental conditions (presumably because of the differences in collisional excitation/relaxation conditions between the TOF MS and FT-ICR MS instruments).

3.5 Evidence for y-Type Fragment Ion Sequence-scrambling: Fig. 4e shows the deconvoluted IM profile of an ion at $m / z 542.3$ (i.e., $\left[\mathrm{y}_{4}\right]^{+}$from MGRYGF) that falls off of the single-component trend line in Fig. 3. These results were perplexing as y-type fragment ions are generally thought to be composed of a single-linear structure [64-67]. Initially, we assumed that either: (1) the ion at $\mathrm{m} / \mathrm{z} 542.3$ was being generated from multiple precursor ions (i.e., FRMYGG, MGRYGF, Gly, and/or PPG); or (2) the synthetic hexapeptides were not pure and 
contained isomeric structure(s). To address the first possibility, the MGRYGF peptide was ran by itself (i.e., not mixed with $\mathrm{Gly}_{6}$, PPG, or FRMYGG) under the same experimental conditions as those used to collect the data in Fig. 3, and similar deconvolution results were obtained (Figure 5a-b), suggesting that the additional component in Fig. 4e did not come from FRMYGG, Gly, , PPG, or any other background species associated with them. This opened the possibility of potential impurities being present in the stock MGRYGF peptide solution; therefore, the MGRYGF peptide was analyzed via ultra-performance liquid chromatography (UPLC)-IM-MS. UPLC-IM-MS results (Supplemental Figure S5) indicated that there was only one (major) component (i.e., MGRYGF) present in MGRYGF samples and there were no isomeric peptides at $m / z 542.3\left(\right.$ i.e., $\left.\left[\mathrm{y}_{4}\right]^{+}\right)$or $m / z, 730.3\left(\right.$ i.e., $\left.\left[\mathrm{M}_{\mathrm{hex}}+\mathrm{H}\right]^{+}\right)$. It is possible, although uncommon, for isomeric peptides to be unresolved by both UPLC and IM [68]. However, deconvolution of the precursor ion at $\mathrm{m} / \mathrm{z} 730.3$ from the PPG/peptide mixture (Fig. 4a) indicated only two IM unresolved peptides, suggesting that the ion at $\mathrm{m} / \mathrm{z} 542.3$ was not being generated from additional peptide isomers. Given these results, our hypothesis was that the ion at $m / z 542.3$ must correspond to two different structures (e.g., sequence-intact $\left[\mathrm{y}_{4}\right]^{+}$and sequence-scrambled $\left[\mathrm{y}_{4}\right]^{+}$from MGRYGF). To test this hypothesis, we analyzed the AIMD deconvoluted CID mass spectra in more detail and performed additional MS experiments.

Previously, we demonstrated that, similar to a- and b-type fragment ions $[38,48,69-76]$, y-type fragment ions could contain additional sequence-scrambled structures [77, 78]. However, in those cases where y-type fragment ion scrambling occurred, first the hydroxyl (or amide) group at the C-terminus had to be lost (as neutral $\mathrm{H}_{2} \mathrm{O}\left(\right.$ or $\left.\mathrm{NH}_{3}\right)$ ) to generate b-"like" fragment ions which could subsequently undergo macrocyclization and sequence-scrambling $[77,78]$. In the present case, an internal glycine residue was observed to be lost $\left(e . g .,\left[y_{3}-G l y\right]^{+}\right.$at $m / z$ 
329.1) without the additional loss of $\mathrm{H}_{2} \mathrm{O}$ (Fig. 5a), suggesting that a portion of the precursor $\mathrm{y}$ type fragment ions (i.e., $\left[\mathrm{y}_{4}\right]^{+}$from MGRYGF at $\mathrm{m} / z$ 542.3) must themselves be sequencescrambled. Similar to our previously reported results for y-type fragment ion rearrangements [78], sequence-scrambling was only observed for the more compact conformer (Figure 5a) with shorter AT of $3.878 \mathrm{~ms}$ (sequence-scrambled fragment ions are denoted by asterisks in Fig. 5). IM deconvolution results in Fig. 4e support the view that sequence-scrambled y-type ions (i.e., $\left[\mathrm{y}_{4}\right]^{+}$) may form a cyclic structure, similar to b-type ions [38, 48, 69-72], which has a smaller collision-cross section (viz., shorter AT of $3.878 \mathrm{~ms}$ ) than conventional linear y-type ions (viz., as compared to longer AT of $4.017 \mathrm{~ms}$ ).

Postulated fragment ion identities of sequence-scrambled fragment ions (named with respect to the original, intact peptide sequence: MGRYGF) in Fig. 5a form a ladder sequence [79] that can be used to ascertain the (potentially) rearranged sequence of the early AT y-type ion at $m / z$ 542.3. For example, the presence of $\left[\mathrm{y}_{3}-\mathrm{Gly}\right]^{+}$at $\mathrm{m} / z 329.1$ in the CID mass spectra of $\left[\mathrm{y}_{4}\right]^{+}$(Fig. 5a) suggests that the C-terminal sequence ends with either YF or FY. Likewise, presence of the ion at $\mathrm{m} / z 468.2\left(\right.$ i.e., $\left.\left[\mathrm{y}_{4}-\mathrm{Gly}+\mathrm{NH}_{3}\right]^{+}\right)$suggests that arginine, tyrosine, and phenylalanine residues are connected to one another, and that glycine is likely at the $\mathrm{N}$-terminal position. Moreover, ions at $m / z$ 155.1, 169.1, 172.1, 180.1, 197.1, and 214.1 (i.e., $\left[\left(\mathrm{b}_{5} \mathrm{y}_{4}\right)_{3}-(\mathrm{Tyr}\right.$ $\left.\left.+\mathrm{CN}_{3} \mathrm{H}_{5}\right)\right]^{+},\left[\left(\mathrm{a}_{5} \mathrm{y}_{4}\right)_{3}-\left(\mathrm{Tyr}+\mathrm{NH}_{3}\right)\right]^{+},\left[\left(\mathrm{b}_{5} \mathrm{y}_{4}\right)_{3}-\left(\mathrm{Tyr}+\mathrm{CN}_{2} \mathrm{H}_{2}\right)\right]^{+},\left[\left(\mathrm{b}_{5} \mathrm{y}_{4}\right)_{3}-\left(\mathrm{Tyr}+\mathrm{N}_{2} \mathrm{H}_{6}\right)\right]^{+}$, $\left[\left(\mathrm{b}_{5} \mathrm{y}_{4}\right)_{3}-\left(\mathrm{Tyr}+\mathrm{NH}_{3}\right)\right]^{+}$, and $\left.\left[\left(\mathrm{b}_{5} \mathrm{y}_{4}\right)_{3}-\mathrm{Tyr}\right)\right]^{+}$, respectively) suggest that arginine and glycine are adjacent to one another. Taken together, we can reason that (at least a portion of) the scrambled amino-acid sequences could be GRYF or GRFY. However, without isotope labeling it is not possible to determine if the glycine is from position two or position five (from the C-terminus) of the original peptide (which would be necessary to determine a potential mechanism). 
Generation of sequence-scrambled y-type fragment ions is unusual but not without precedence. In 2014 Gonzalez-Sanchez et al. reported a potentially sequence-scrambled y-type fragment ion (i.e., $\left[\mathrm{y}_{10}-\mathrm{Ala}\right]^{2+}(\mathrm{m} / z$ 581.3)) generated from CID of [FVIAFIL(p)HLV(p)K + $2 \mathrm{H}]^{2+}$ (where "(p)" denotes possible phosphorylation of the following histidine or lysine residues)) [80]. They reasoned that if protonation of the C-terminal basic amino acid(s) enhanced $y$-fragment scrambling, then the phosphorylation site must be at the histidine residue rather than the lysine residue [80].

Because of the unusual nature of y-type fragment ion scrambling, we performed additional experiments to further investigate the fragment ions at $\mathrm{m} / \mathrm{z} 542.3$ (i.e., $\left[\mathrm{y}_{4}\right]^{+}$from MGRYGF; Fig. 5d). Specifically, we isolated the ions at $\mathrm{m} / \mathrm{z} 542.3$ (generated from in-source CID of MGRYGF) using an LTQ-Orbitrap and performed CID on the isolated ions to generate the mass spectra in Fig. 5d. CID of isolated $\mathrm{m} / \mathrm{z} 542.3$ (Fig. 5d) generated rearranged product fragment ions similar to those observed in Synapt G2-S experiments (Fig. 5a). Specifically, rearranged MGRYGF fragment ions were noted at $m / z$ 's 169.1, 214.1, 329.2, and 370.2 corresponding to $\left[\left(\mathrm{a}_{5} \mathrm{y}_{4}\right)_{3}-\left(\mathrm{Tyr}+\mathrm{NH}_{3}\right)\right]^{+},\left[\left(\mathrm{b}_{5} \mathrm{y}_{4}\right)_{3}-(\mathrm{Tyr})\right]^{+},\left[\mathrm{y}_{3}-(\mathrm{Gly})\right]^{+}$, and $\left[\mathrm{y}_{4}-(\mathrm{Gly}+\right.$ $\left.\left.\mathrm{C}_{4} \mathrm{~N}_{3} \mathrm{H}_{9} \mathrm{O}\right)\right]^{+}$, respectively. Intriguingly, when the fragment ion at $\mathrm{m} / z 542.3$ was first generated from CID of $m / z 730.3$ (i.e., $\left[\mathbf{M}_{\text {hex }}+\mathrm{H}\right]^{+}$) or $m / z 365.2$ (i.e., $\left[\mathbf{M}_{\text {hex }}+2 \mathrm{H}\right]^{2+}$, data not shown), and then isolated/fragmented, no detectable rearranged species were observed to be generated (Fig. 5c). Taken together, MS data from the Synapt G2-S (Fig. 5a-b) and the Orbitrap (Fig. 5c-d) suggest that rearrangement of the $\left[\mathrm{y}_{4}\right]^{+}$fragment of MGRYGF occurs in-source (i.e., during the ESI event). However, without further study of the ions identified in this manuscript, and/or those reported by Gonzalez-Sanchez et al., it is impossible to draw concrete conclusions of the mechanism or extent of y-type fragment ion scrambling. These types of investigations are 
outside the scope of the current manuscript but warrant further investigation in an independent study. Regardless of the mechanism of formation, because y-type fragment ions are generally thought to correspond to a single-linear sequence [64-67], we had no reason to expect y-type fragment ions to fall off of the single-component trend line; these results highlight the utility of FWHH peak analysis using IM_FIT to identify IM unresolved species that would otherwise be overlooked.

\section{CONCLUSION}

Previously, we showed how IM unresolved species could be deconvoluted using the AIMD software [39]. One limitation of AIMD, however, is that it is only useful for targeted analysis of IM profiles that are already expected to contain more than one component. Using IM_FIT, users can systematically identify compounds in complex mixtures that are likely to correspond to multiple components for subsequent targeted analysis using AIMD or other deconvolution techniques. Hence, IM_FIT can enable high-throughput IM characterization of IM unresolved species in complex mixtures (e.g., blood, oil, tissue extracts, etc.) without requiring any additional experimental steps such as ion isolation or fragmentation. When used in conjunction with IM deconvolution techniques, such as AIMD, IM_FIT can be used to more fully characterize samples by tagging peaks that potentially contain multiple (previously undetected) isomeric or isobaric species.

The system analyzed in this study (i.e., polypropylene glycol, FRMYGG, MGRYGF, and Gly $_{6}$ ) was shown to produce a single-conformer trend line as well as multiple IM convoluted species. After using IM_FIT to identify potential IM co-elution, species that were determined to deviate from the trend line were individually analyzed using various techniques (i.e., post- 
IM/CID MS and chemometric deconvolution, FT-ICR MS, Orbitrap MS, and LC-IM-MS). Of the fourteen peaks identified as potential co-elution by IM_FIT (eight above action limit and six above warning limit, Table 1), nine corresponded to peptide ions and were all positively identified as corresponding to multiple components. The remaining five potentially co-eluting peaks corresponded to PPG adducts, of which only the three $\left[\mathrm{PPG}_{\mathrm{n}}+\mathrm{Na}\right]^{+}$peaks $($where $\mathrm{n}=6-8)$ were further characterized as multiple components. The remaining two $\left[\mathrm{PPG}_{\mathrm{n}}+\mathrm{K}\right]^{+}$peaks were not further characterized, as $\left[\mathrm{PPG}_{\mathrm{n}}+\mathrm{K}\right]^{+}$peaks were found to deviate in both the mixture (Fig. 3, solid squares) and PPG-only (data not shown) experiments from the $\left[\mathrm{PPG}_{\mathrm{n}}+\mathrm{Na}\right]^{+}$trend line. An additional discovery made using IM_FIT was the unusual y-type fragment scrambling observed from the $\left[\mathrm{y}_{4}\right]^{+}$fragment of MGRYGF. Further analysis using LC-IM-MS and MS/MS Orbitrap of the $\left[\mathrm{y}_{4}\right]^{+}$fragment revealed that scrambling occurred in-source and was reproducible across instrument platforms (i.e. Synapt G2-S and Orbitrap).

\section{ACKNOWLEDGEMENTS}

The authors would like to acknowledge the financial support provided by the National Science Foundations (NSF) (NSF-IDBR Award \# 1455668). Any opinions, findings, conclusion, or recommendations expressed in this material are those of the authors' and do not necessarily reflect the views of the NSF. The authors are also grateful for financial support from Baylor University (CFRIP 30300152). 


\section{REFERENCES}

[1] X. Han, K. Yang, R.W. Gross, Multi-dimensional mass spectrometry-based shotgun lipidomics and novel strategies for lipidomic analyses, Mass spectrometry reviews, 31 (2012) 134-178.

[2] S.J. Blanksby, T.W. Mitchell, Advances in mass spectrometry for lipidomics, Annual Review of Analytical Chemistry, 3 (2010) 433-465.

[3] R.J. Mishur, S.L. Rea, Applications of mass spectrometry to metabolomics and metabonomics: Detection of biomarkers of aging and of age-related diseases, Mass spectrometry reviews, 31 (2012) 7095.

[4] C.S. Hsu, C.L. Hendrickson, R.P. Rodgers, A.M. McKenna, A.G. Marshall, Petroleomics: advanced molecular probe for petroleum heavy ends, Journal of Mass Spectrometry, 46 (2011) 337-343.

[5] A.G. Marshall, R.P. Rodgers, Petroleomics: Chemistry of the underworld, Proceedings of the National Academy of Sciences, 105 (2008) 18090-18095.

[6] A. Bensimon, A.J. Heck, R. Aebersold, Mass spectrometry-based proteomics and network biology, Annual review of biochemistry, 81 (2012) 379-405.

[7] H. Budzikiewicz, C. Djerassi, D.H. Williams, Mass spectrometry of organic compounds, (1964).

[8] F.W. McLafferty, F. Tureček, Interpretation of mass spectra, University Science Books1993.

[9] Z. Wu, R.P. Rodgers, A.G. Marshall, Two-and three-dimensional van Krevelen diagrams: A graphical analysis complementary to the Kendrick mass plot for sorting elemental compositions of complex organic mixtures based on ultrahigh-resolution broadband Fourier transform ion cyclotron resonance mass measurements, Analytical chemistry, 76 (2004) 2511-2516.

[10] E. Kendrick, A Mass Scale Based on $\mathrm{CH} 2=14.0000$ for High Resolution Mass Spectrometry of Organic Compounds, Analytical Chemistry, 35 (1963) 2146-2154.

[11] A.G. Marshall, C.L. Hendrickson, G.S. Jackson, Fourier transform ion cyclotron resonance mass spectrometry: a primer, Mass spectrometry reviews, 17 (1998) 1-35.

[12] F. Xian, C.L. Hendrickson, A.G. Marshall, High resolution mass spectrometry, Analytical chemistry, 84 (2012) 708-719.

[13] C.D. Wenger, G.C. McAlister, Q. Xia, J.J. Coon, Sub-part-per-million precursor and product mass accuracy for high-throughput proteomics on an electron transfer dissociation-enabled orbitrap mass spectrometer, Molecular \& Cellular Proteomics, 9 (2010) 754-763.

[14] R.A. Zubarev, A. Makarov, Orbitrap mass spectrometry, Analytical chemistry, 85 (2013) 5288-5296.

[15] T. Solouki, J.E. Szulejko, Bimolecular and unimolecular contributions to the disparate self-chemical ionizations of $\alpha$-Pinene and camphene isomers, Journal of the American Society for Mass Spectrometry, 18 (2007) 2026-2039.

[16] A. Ahmed, S. Kim, Atmospheric Pressure Photo Ionization Hydrogen/Deuterium Exchange Mass Spectrometry-a Method to Differentiate Isomers by Mass Spectrometry, Journal of the American Society for Mass Spectrometry, 24 (2013) 1900-1905.

[17] P. Donato, F. Cacciola, P.Q. Tranchida, P. Dugo, L. Mondello, Mass spectrometry detection in comprehensive liquid chromatography: basic concepts, instrumental aspects, applications and trends, Mass spectrometry reviews, 31 (2012) 523-559.

[18] R.L. Grob, E.F. Barry, Modern practice of gas chromatography, John Wiley \& Sons2004.

[19] J.A. McLean, B.T. Ruotolo, K.J. Gillig, D.H. Russell, Ion mobility-mass spectrometry: a new paradigm for proteomics, International Journal of Mass Spectrometry, 240 (2005) 301-315.

[20] J.C. May, J.A. McLean, Ion mobility-mass spectrometry: time-dispersive instrumentation, Analytical chemistry, 87 (2015) 1422-1436.

[21] G.R. Asbury, H.H. Hill, Using different drift gases to change separation factors $(\alpha)$ in ion mobility spectrometry, Analytical chemistry, 72 (2000) 580-584. 
[22] K. Giles, J.P. Williams, I. Campuzano, Enhancements in travelling wave ion mobility resolution, Rapid Communications in Mass Spectrometry, 25 (2011) 1559-1566.

[23] W.S. Barnes, Mobility measurements of ions in nitrogen and hydrogen with simultaneous mass identification of the ionic species, (1963).

[24] C.W. Damen, W. Chen, A.B. Chakraborty, M. van Oosterhout, J.R. Mazzeo, J.C. Gebler, J.H. Schellens, H. Rosing, J.H. Beijnen, Electrospray ionization quadrupole ion-mobility time-of-flight mass spectrometry as a tool to distinguish the lot-to-lot heterogeneity in $\mathrm{N}$-glycosylation profile of the therapeutic monoclonal antibody trastuzumab, J. Am. Soc. Mass Spectrom., 20 (2009) 2021-2033.

[25] D.J. Weston, R. Bateman, I.D. Wilson, T.R. Wood, C.S. Creaser, Direct analysis of pharmaceutical drug formulations using ion mobility spectrometry/quadrupole-time-of-flight mass spectrometry combined with desorption electrospray ionization, Analytical chemistry, 77 (2005) 7572-7580.

[26] K. McAfee Jr, D. Edelson, Identification and mobility of ions in a Townsend discharge by timeresolved mass spectrometry, Proceedings of the Physical Society, 81 (1963) 382.

[27] S.M. Zucker, S. Lee, N. Webber, S.J. Valentine, J.P. Reilly, D.E. Clemmer, An ion mobility/ion trap/photodissociation instrument for characterization of ion structure, J. Am. Soc. Mass Spectrom., 22 (2011) 1477-1485.

[28] X. Liu, M. Plasencia, S. Ragg, S.J. Valentine, D.E. Clemmer, Development of high throughput dispersive LC-ion mobility-TOFMS techniques for analysing the human plasma proteome, Briefings in functional genomics \& proteomics, 3 (2004) 177-186.

[29] A.E. Hilderbrand, S. Myung, C.A.S. Barnes, D.E. Clemmer, Development of LC-IMS-CID-TOFMS techniques: analysis of a 256 component tetrapeptide combinatorial library, J. Am. Soc. Mass Spectrom., 14 (2003) 1424-1436.

[30] C.L. Crawford, S. Graf, M. Gonin, K. Fuhrer, X. Zhang, H.H. Hill Jr, The novel use of gas chromatography-ion mobility-time of flight mass spectrometry with secondary electrospray ionization for complex mixture analysis, International Journal for Ion Mobility Spectrometry, 14 (2011) 23-30.

[31] S.D. Pringle, K. Giles, J.L. Wildgoose, J.P. Williams, S.E. Slade, K. Thalassinos, R.H. Bateman, M.T. Bowers, J.H. Scrivens, An investigation of the mobility separation of some peptide and protein ions using a new hybrid quadrupole/travelling wave IMS/oa-ToF instrument, International Journal of Mass Spectrometry, 261 (2007) 1-12.

[32] K. Giles, J.L. Wildgoose, S. Pringle, D. Langridge, P. Nixon, J. Garside, P. Carney, Characterising a TWave Enabled Multi-Pass Cyclic Ion Mobility Separator, Proceedings of the 63rd ASMS Conference on Mass Spectrometry and Allied Topics, (2015) 61.

[33] F.A. Fernandez-Lima, C. Becker, A.M. McKenna, R.P. Rodgers, A.G. Marshall, D.H. Russell, Petroleum crude oil characterization by IMS-MS and FTICR MS, Analytical chemistry, 81 (2009) 9941-9947.

[34] S.J. Valentine, M.D. Plasencia, X. Liu, M. Krishnan, S. Naylor, H.R. Udseth, R.D. Smith, D.E. Clemmer, Toward plasma proteome profiling with ion mobility-mass spectrometry, Journal of proteome research, 5 (2006) 2977-2984.

[35] R.D. Smith, G.A. Anderson, M.S. Lipton, C. Masselon, L. Paša-Tolic, Y. Shen, H.R. Udseth, Review: The Use of Accurate Mass Tags for High-Throughput Microbial Proteomics, Omics: a journal of integrative biology, 6 (2002) 61-90.

[36] M.D. Plasencia, D. Isailovic, S.I. Merenbloom, Y. Mechref, D.E. Clemmer, Resolving and assigning Nlinked glycan structural isomers from ovalbumin by IMS-MS, J. Am. Soc. Mass Spectrom., 19 (2008) 1706-1715.

[37] B. Zekavat, T. Solouki, Chemometric data analysis for deconvolution of overlapped ion mobility profiles, Journal of the American Society for Mass Spectrometry, 23 (2012) 1873-1884.

[38] B. Zekavat, M. Miladi, C. Becker, S. Munisamy, T. Solouki, Combined Use of Post-Ion Mobility/Collision-Induced Dissociation and Chemometrics for b Fragment Ion Analysis, J. Am. Soc. Mass Spectrom., 24 (2013) 1355-1365. 
[39] M. Brantley, B. Zekavat, B. Harper, R. Mason, T. Solouki, Automated deconvolution of overlapped ion mobility profiles, Journal of the American Society for Mass Spectrometry, 25 (2014) 1810-1819.

[40] M. Pettit, B. Harper, M. Brantley, T. Solouki, Collision-energy Resolved Ion Mobility Characterization of Isomeric Mixtures, Analyst, 140 (2015) 6886-6896.

[41] S. Garmón-Lobato, B. Abad-García, M. Sánchez-llárduya, M. Romera-Fernández, L. Berrueta, B. Gallo, F. Vicente, Improvement using chemometrics in ion mobility coupled to mass spectrometry as a tool for mass spectrometry fragmentation studies: Flavonoid aglycone cases, Analytica chimica acta, 771 (2013) 56-64.

[42] W. Hoffmann, J. Hofmann, K. Pagel, Energy-resolved ion mobility-mass spectrometry-a concept to improve the separation of isomeric carbohydrates, J. Am. Soc. Mass Spectrom., 25 (2014) 471-479.

[43] S. Lee, Z. Li, S.J. Valentine, S.M. Zucker, N. Webber, J.P. Reilly, D.E. Clemmer, Extracted fragment ion mobility distributions: A new method for complex mixture analysis, International Journal of Mass Spectrometry, 309 (2012) 154-160.

[44] M. Miladi, B. Zekavat, S.M. Munisamy, T. Solouki, A systematic study on the effect of histidine position and fragment ion size on the formation of bn ions, International Journal of Mass Spectrometry, 316-318 (2012) 164-173.

[45] K. Jeanne Dit Fouque, C. Afonso, S. Zirah, J.D. Hegemann, M. Zimmermann, M.A. Marahiel, S. Rebuffat, H. Lavanant, Ion Mobility-Mass Spectrometry of Lasso Peptides: Signature of a Rotaxane Topology, Analytical chemistry, 87 (2014) 1166-1172.

[46] J.E. Bartmess, R.M. Georgiadis, Empirical methods for determination of ionization gauge relative sensitivities for different gases, Vacuum, 33 (1983) 149-153.

[47] M. Miladi, A.D. Olaitan, B. Zekavat, T. Solouki, Competing noncovalent host-guest interactions and $\mathrm{H} / \mathrm{D}$ exchange: reactions of benzyloxycarbonyl-proline glycine dipeptide variants with $\mathrm{ND}_{3}$, J. Am. Soc. Mass Spectrom., 26 (2015) 1938-1949.

[48] B. Zekavat, M. Miladi, A. Al-Fdeilat, A. Somogyi, T. Solouki, Evidence for Sequence Scrambling and Divergent H/D Exchange Reactions of Doubly-Charged Isobaric b-Type Fragment lons, J. Am. Soc. Mass Spectrom., 25 (2014) 226-236.

[49] J. Gauthier, T. Trautman, D. Jacobson, Sustained Off-Resonance Irradiation for Collision-Activated Dissociation Involving FT-ICR-MS. CID Technique That Emulates Infrared Multiphoton Dissociation, Anal. Chim. Acta, 246 (1991) 211-225.

[50] E.W. Weisstein, Gaussian Function, A Wolfram Web Resource, Mathworld, 2002.

[51] S. McKinley, M. Levine, Cubic spline interpolation, College of the Redwoods, 45 (1998) 1049-1060.

[52] S. Valentine, A. Counterman, C. Hoaglund, J. Reilly, D. Clemmer, Gas-phase separations of protease digests, J. Am. Soc. Mass Spectrom., 9 (1998) 1213-1216.

[53] B.T. Ruotolo, J.L. Benesch, A.M. Sandercock, S.-J. Hyung, C.V. Robinson, Ion mobility-mass spectrometry analysis of large protein complexes, Nature Protocols, 3 (2008) 1139-1152.

[54] S.J. Valentine, A.E. Counterman, D.E. Clemmer, A database of 660 peptide ion cross sections: use of intrinsic size parameters for bona fide predictions of cross sections, J. Am. Soc. Mass Spectrom., 10 (1999) 1188-1211.

[55] L. Tao, J.R. McLean, J.A. McLean, D.H. Russell, A collision cross-section database of singly-charged peptide ions, J. Am. Soc. Mass Spectrom., 18 (2007) 1232-1238.

[56] A.A. Shvartsburg, R.D. Smith, Fundamentals of Traveling Wave Ion Mobility Spectrometry, Analytical Chemistry, 80 (2008) 9689-9699.

[57] R.R. Hudgins, Y. Mao, M.A. Ratner, M.F. Jarrold, Conformations of Gly $\mathrm{n} H+$ and Ala $\mathrm{n} H+$ Peptides in the Gas Phase, Biophysical journal, 76 (1999) 1591-1597.

[58] P. Roepstorff, J. Fohlman, Proposal for a nomenclature for sequence ions in mass spectra of pep tides., Biomed. Mass Spec, 11 (1984) 601. 
[59] C. Uetrecht, R.J. Rose, E. van Duijn, K. Lorenzen, A.J. Heck, Ion mobility mass spectrometry of proteins and protein assemblies, Chemical Society Reviews, 39 (2010) 1633-1655.

[60] S.I. Merenbloom, T.G. Flick, E.R. Williams, How hot are your ions in TWAVE ion mobility spectrometry?, Journal of the American Society for Mass Spectrometry, 23 (2012) 553-562.

[61] J. Gidden, T. Wyttenbach, A.T. Jackson, J.H. Scrivens, M.T. Bowers, Gas-phase conformations of synthetic polymers: poly (ethylene glycol), poly (propylene glycol), and poly (tetramethylene glycol), Journal of the American Chemical Society, 122 (2000) 4692-4699.

[62] W. Windig, J. Guilment, Interactive self-modeling mixture analysis, Analytical chemistry, 63 (1991) $1425-1432$.

[63] S. Trimpin, D.E. Clemmer, lon mobility spectrometry/mass spectrometry snapshots for assessing the molecular compositions of complex polymeric systems, Analytical chemistry, 80 (2008) 9073-9083.

[64] D.R. Mueller, M. Eckersley, W. Richter, Hydrogen transfer reactions in the formation of " $\mathrm{Y}^{+2 \text { " }}$ sequence ions from protonated peptides., Org. Mass Spectrom., 23 (1988) 217-222.

[65] M.M. Cordero, J.J. Houser, C. Wesdemiotis, The neutral products formed during backbone fragmentations of protonated peptides in tandem mass spectrometry, Anal. Chem., 65 (1993) 15941601.

[66] L. Yu, Y. Tan, Y. Tsai, D.R. Goodlett, N.C. Polfer, On the relevance of Peptide sequence permutations in shotgun proteomics studies, J. Proteome. Res., 10 (2011) 2409-2416.

[67] A. Goloborodko, M. Gorshkov, D. Good, R. Zubarev, Sequence Scrambling in Shotgun Proteomics is Negligible, J. Am. Soc. Mass Spectrom., 22 (2011) 1121-1124.

[68] C.A. Srebalus Barnes, A.E. Hilderbrand, S.J. Valentine, D.E. Clemmer, Resolving Isomeric Peptide Mixtures: A Combined HPLC/Ion Mobility-TOFMS Analysis of a 4000-Component Combinatorial Library, Analytical Chemistry, 74 (2002) 26-36.

[69] X. Chen, J.D. Steill, J. Oomens, N.C. Polfer, Oxazolone versus macrocycle structures for leuenkephalin $b_{2}-b_{4}$ : insights from infrared multiple-photon dissociation spectroscopy and gas-phase hydrogen/deuterium exchange, J. Am. Soc. Mass Spectrom., 21 (2010) 1313-1321.

[70] X. Chen, F. Turecek, Simple b ions have cyclic oxazolone structures. A neutralization-reionization mass spectrometric and computational study of oxazolone radicals, J. Am. Soc. Mass Spectrom., 16 (2005) 1941-1956.

[71] X. Chen, L. Yu, J.D. Steill, J. Oomens, N.C. Polfer, Effect of peptide fragment size on the propensity of cyclization in collision-induced dissociation: Oligoglycine $b_{2}-b_{8}$, J. Am. Chem. Soc., 131 (2009) 1827218282.

[72] M. Tirado, N.C. Polfer, Defying entropy: forming large head-to-tail macrocycles in the gas phase, Angew. Chem. Int. Ed. Engl., 124 (2012) 1-4.

[73] X.J. Tang, R.K. Boyd, Rearrangements of doubly charged acylium ions from lysyl and ornithyl peptides, Rapid. Commun. Mass. Spectrom., 8 (1994) 678-686.

[74] X.J. Tang, P. Thibault, R.K. Boyd, Fragmentation reactions of multiply-protonated peptides and implications for sequencing by tandem mass spectrometry with low-energy collision-induced dissociation, Anal. Chem., 65 (1993) 2824-2834.

[75] I. Riba Garcia, K. Giles, R.H. Bateman, S.J. Gaskell, Studies of peptide a- and b-type fragment ions using stable isotope labeling and integrated ion mobility/tandem mass spectrometry, J. Am. Soc. Mass Spectrom., 19 (2008) 1781-1787.

[76] I. Riba-Garcia, K. Giles, R.H. Bateman, S.J. Gaskell, Evidence for structural variants of a- and b-type peptide fragment ions using combined ion mobility/mass spectrometry, J. Am. Soc. Mass Spectrom., 19 (2008) 609-613.

[77] M. Miladi, B. Harper, T. Solouki, Evidence for Sequence Scrambling in Collision-Induced Dissociation of y-Type Fragment lons, J. Am. Soc. Mass Spectrom., 24 (2013) 1755-1766. 
[78] B. Harper, M. Miladi, T. Solouki, Loss of internal backbone carbonyls: additional evidence for sequence-scrambling in collision-induced dissociation of y-type ions, Journal of the American Society for Mass Spectrometry, 25 (2014) 1716-1729.

[79] B.T. Chait, R. Wang, R.C. Beavis, S. Kent, Protein ladder sequencing, Science, 262 (1993) 89-92.

[80] M.-B. Gonzalez-Sanchez, F. Lanucara, G.E. Hardman, C.E. Eyers, Gas-phase intermolecular phosphate transfer within a phosphohistidine phosphopeptide dimer, International Journal of Mass Spectrometry, 367 (2014) 28-34. 
Table 1. Summary calculations for all peaks identified by IM_FIT

\begin{tabular}{|c|c|c|c|c|c|}
\hline $\begin{array}{c}\text { Arrival } \\
\text { Time (ms) }\end{array}$ & $m / z$ & $\begin{array}{l}\text { Peak Width } \\
(\mathrm{ms})^{*}\end{array}$ & Zone & Assignment & $\begin{array}{c}\text { Co-elution } \\
\text { Analysis }\end{array}$ \\
\hline $2.292( \pm .001)$ & 287.2 & $0.133( \pm .001)$ & - & FRMYGG; $\left[\mathrm{b}_{2}-\mathrm{NH}_{3}\right]^{+}$ & - \\
\hline $2.297( \pm .001)$ & 304.2 & $0.131( \pm .003)$ & - & FRMYGG; $\left[\mathrm{b}_{2}\right]^{+}$ & - \\
\hline $2.412( \pm .001)$ & 331.2 & $0.127( \pm .002)$ & - & {$\left[\mathrm{PPG}_{5}+\mathrm{Na}\right]^{+}$} & - \\
\hline $2.770( \pm .002)$ & 389.3 & $0.154( \pm .010)$ & Action & {$\left[\mathrm{PPG}_{6}+\mathrm{Na}\right]^{+}$} & Pure PPG \\
\hline $2.771( \pm .002)$ & 390.3 & $0.132( \pm .003)$ & - & {$\left[\mathrm{PPG}_{6}+\mathrm{Na}\right]^{+}$} & - \\
\hline $2.481( \pm .001)$ & 399.1 & $0.126( \pm .003)$ & - & {$\left[\mathrm{Gly}_{6}+\mathrm{K}\right]^{+}$} & - \\
\hline $2.827( \pm .003)$ & 405.2 & $0.194( \pm .001)$ & Action & {$\left[\mathrm{PPG}_{6}+\mathrm{K}\right]^{+}$} & - \\
\hline $3.177( \pm .001)$ & 407.2 & $0.162( \pm .003)$ & - & FRMYGG; $\left[\mathrm{a}_{3}\right]^{+}$ & - \\
\hline $3.370( \pm .001)$ & 435.2 & $0.167( \pm .001)$ & - & FRMYGG; $\left[b_{3}\right]^{+}$ & - \\
\hline $3.158( \pm .001)$ & 447.3 & $0.175( \pm .002)$ & Warning & {$\left[\mathrm{PPG}_{7}+\mathrm{Na}\right]^{+}$} & Pure PPG \\
\hline $3.158( \pm .003)$ & 448.3 & $0.155( \pm .001)$ & - & {$\left[\mathrm{PPG}_{7}+\mathrm{Na}\right]^{+}$} & - \\
\hline $3.193( \pm .001)$ & 463.3 & $0.241( \pm .003)$ & Action & {$\left[\mathrm{PPG}_{7}+\mathrm{K}\right]^{+}$} & - \\
\hline $3.578( \pm .001)$ & 505.3 & $0.188( \pm .003)$ & Warning & {$\left[\mathrm{PPG}_{8}+\mathrm{Na}\right]^{+}$} & Pure PPG \\
\hline $3.578( \pm .002)$ & 506.4 & $0.167( \pm .002)$ & - & {$\left[\mathrm{PPG}_{8}+\mathrm{Na}\right]^{+}$} & - \\
\hline $4.027( \pm .002)$ & 542.3 & $0.217( \pm .001)$ & Warning & MGRYGF; $\left[\mathrm{y}_{4}\right]^{+}$ & $\begin{array}{l}\text { AIMD, LC-IM- } \\
\text { MS }^{* *} \text {, Orbitrap }\end{array}$ \\
\hline $4.023( \pm .002)$ & 563.4 & $0.183( \pm .001)$ & - & {$\left[\mathrm{PPG}_{9}+\mathrm{Na}\right]^{+}$} & - \\
\hline $4.174( \pm .002)$ & 565.3 & $0.202( \pm .002)$ & - & MGRYGF; $\left[b_{5}\right]^{+}$ & - \\
\hline $4.448( \pm .003)$ & 570.3 & $0.307( \pm .004)$ & Action & FRMYGG; $\left[\mathrm{a}_{4}\right]^{+}$ & Visual \\
\hline $4.148( \pm .001)$ & 583.3 & $0.205( \pm .002)$ & - & FRMYGG; $\left[y_{5}\right]^{+}$ & - \\
\hline $4.319( \pm .001)$ & 598.3 & $0.241( \pm .002)$ & Action & FRMYGG; $\left[b_{4}\right]^{+}$ & $\begin{array}{l}\text { AIMD, Isotopic } \\
\text { Abundance }^{+}\end{array}$ \\
\hline $4.318( \pm .002)$ & 599.3 & $0.269( \pm .003)$ & Action & MGRYGF; $\left[\mathrm{y}_{5}\right]^{+}$ & $\begin{array}{l}\text { AIMD, Isotopic } \\
\text { Abundance }{ }^{\dagger}, \mathrm{FT}- \\
\mathrm{ICR}^{\S}\end{array}$ \\
\hline $4.320( \pm .002)$ & 600.3 & $0.256( \pm .002)$ & Action & FRMYGG; $\left[\mathrm{y}_{5}+\mathrm{NH}_{3}\right]^{+}$ & $\begin{array}{l}\text { AIMD, Isotopic } \\
\text { Abundance }^{+}\end{array}$ \\
\hline $4.318( \pm .003)$ & 601.3 & $0.229( \pm .003)$ & Warning & Combination of Isotopes & $\begin{array}{l}\text { Isotopic } \\
\text { Abundance }^{+}\end{array}$ \\
\hline $4.602( \pm .003)$ & 609.3 & $0.224( \pm .002)$ & - & Unknown Contaminate & - \\
\hline $4.559( \pm .002)$ & 621.4 & $0.211( \pm .002)$ & - & {$\left[\mathrm{PPG}_{10}+\mathrm{Na}\right]^{+}$} & - \\
\hline $4.885( \pm .002)$ & 655.3 & $0.226( \pm .003)$ & - & FRMYGG $\left(b_{5}\right)^{+}$ & - \\
\hline $5.100( \pm .003)$ & 679.5 & $0.230( \pm .003)$ & - & {$\left[\mathrm{PPG}_{11}+\mathrm{Na}\right]^{+}$} & - \\
\hline $5.412( \pm .002)$ & 730.3 & $0.305( \pm .002)$ & Action & Hexapeptides; $[\mathrm{M}+\mathrm{H}]^{+}$ & AIMD \\
\hline $5.412( \pm .001)$ & 731.3 & $0.282( \pm .001)$ & Warning & Hexapeptides; $[\mathrm{M}+\mathrm{H}]^{+}$ & AIMD \\
\hline $5.415( \pm .002)$ & 732.3 & $0.278( \pm .002)$ & Warning & Hexapeptides; $[\mathrm{M}+\mathrm{H}]^{+}$ & AIMD \\
\hline $5.704( \pm .005)$ & 737.5 & $0.269( \pm .005)$ & - & {$\left[\mathrm{PPG}_{12}+\mathrm{Na}\right]^{+}$} & - \\
\hline $6.281( \pm .005)$ & 795.5 & $0.299( \pm .001)$ & - & {$\left[\mathrm{PPG}_{13}+\mathrm{Na}\right]^{+}$} & - \\
\hline $6.872( \pm .005)$ & 853.6 & $0.330( \pm .003)$ & - & {$\left[\mathrm{PPG}_{14}+\mathrm{Na}\right]^{+}$} & - \\
\hline \multicolumn{6}{|c|}{$\begin{array}{l}\text { Based on Gaussian fitted distributions measured at half height (FWHH). Errors are reported at the } 95 \% \\
\text { confidence interval for three experimental replicates. }\end{array}$} \\
\hline $\begin{array}{l}{ }^{*} \text { Based on Gaus } \\
\text { confidence inter } \\
{ }^{* *} \text { LC-IM-MS cl } \\
{ }^{\dagger} \text { Isotopic abund }\end{array}$ & $\begin{array}{l}\text { ian fitte } \\
\text { val for } \mathrm{t} \\
\text { romato }\end{array}$ & $\begin{array}{l}\text { distributions } m \\
\text { rree experimenta } \\
\text { rams are present }\end{array}$ & replicates. & $\begin{array}{l}\text { If height (FWHH). Errors } \\
\text { nental Figure S5. }\end{array}$ & e reported at the $95^{\circ}$ \\
\hline
\end{tabular}




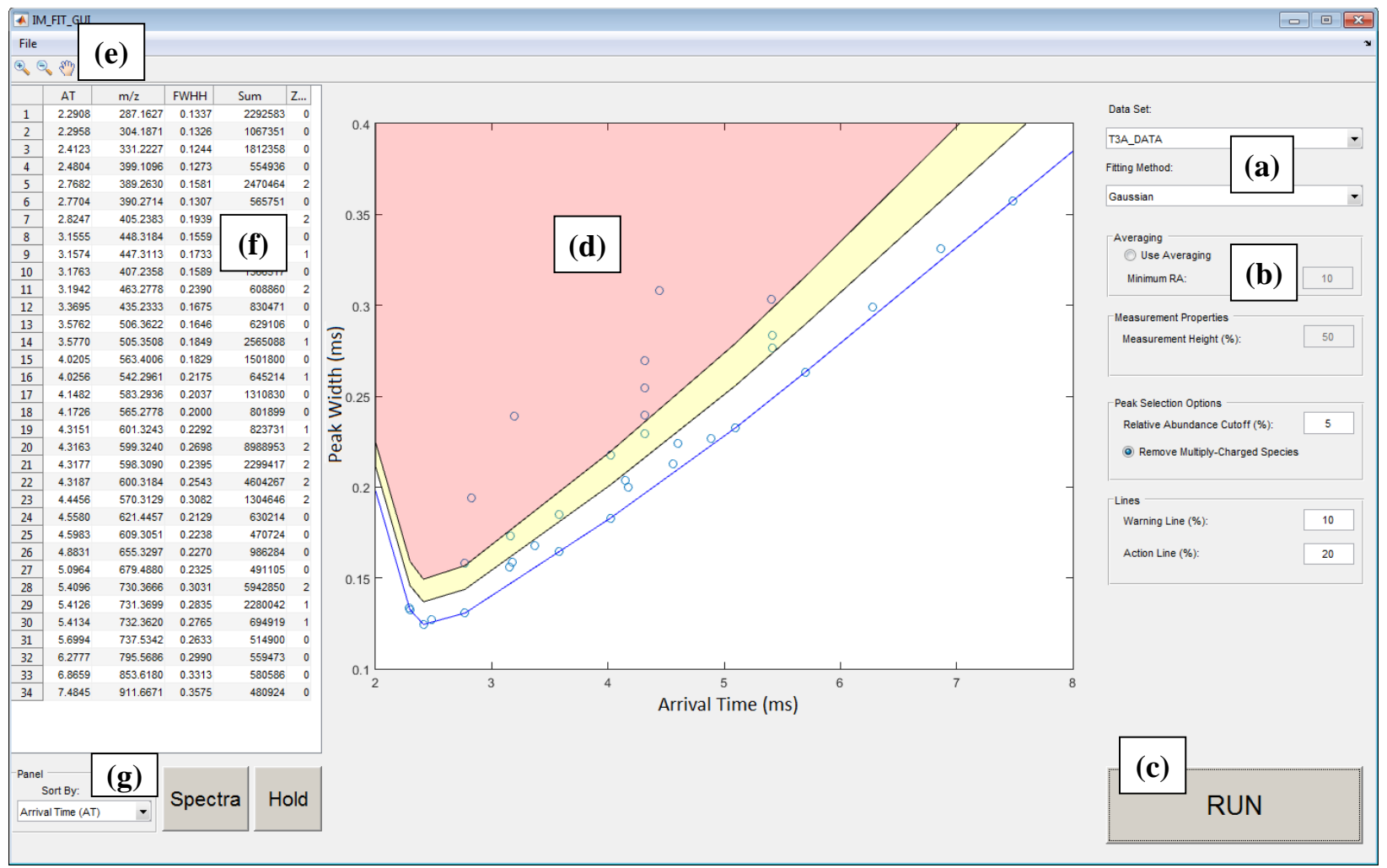

Fig 1: Screen capture of the IM_FIT GUI after analysis of PPG spiked with the peptides MGFRYG, MFRYGG, and GGGGGG. a) Controls for selecting data set and fitting method, b) controls for enabling or disabling of peak averaging, selecting measurement height (for raw and cubic spline interpolation), and a minimum peak relative abundance cutoff, c) "RUN" button to start the analysis process, d) display window that can show either the FWHH as a function of arrival time or be selected to display the fitted mobiligram, e) controls for zooming in, zooming out, and panning the display window, respectively, f) data table displaying the arrival time (AT), $m / z, F W H H$, and summed intensity across the mobiligram, g) controls for modifying the sort order for the data table and toggling between the fitted mobiligram and FWHH vs AT plot. 

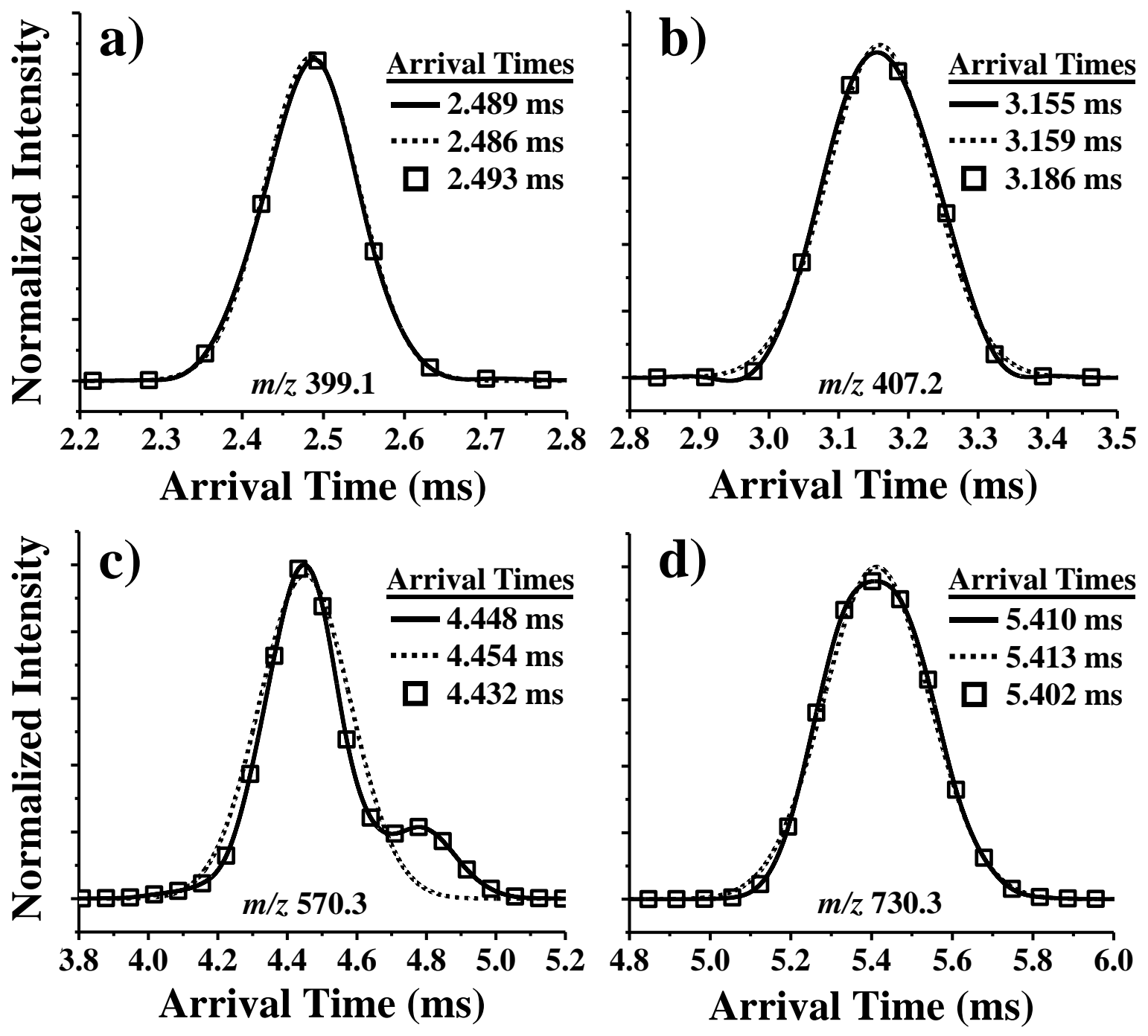

Fig 2. Comparison of fitting methods for IM profiles of $m / z$ a) $399.1\left(\right.$ i.e., $\left[\mathrm{Gly}_{6}+\mathrm{K}\right]^{+}$), b) 407.2 (i.e., $\left[\mathrm{a}_{3}\right]^{+}$fragment of FRMYGG), c) 570.3 (i.e., $\left[\mathrm{a}_{4}\right]^{+}$fragment of FRMYGG), and d) 730.3 (i.e., $\left[\mathrm{M}_{\mathrm{hex}}+\mathrm{H}\right]^{+}$for both FRMYGG and MGRYGF) with raw data shown as open squares ( $\square$ ), Gaussian fits shown as dotted lines, and cubic spline interpolations shown as solid lines. Listed arrival times, in millisecond, correspond to maxima for selected IM peak fits. 


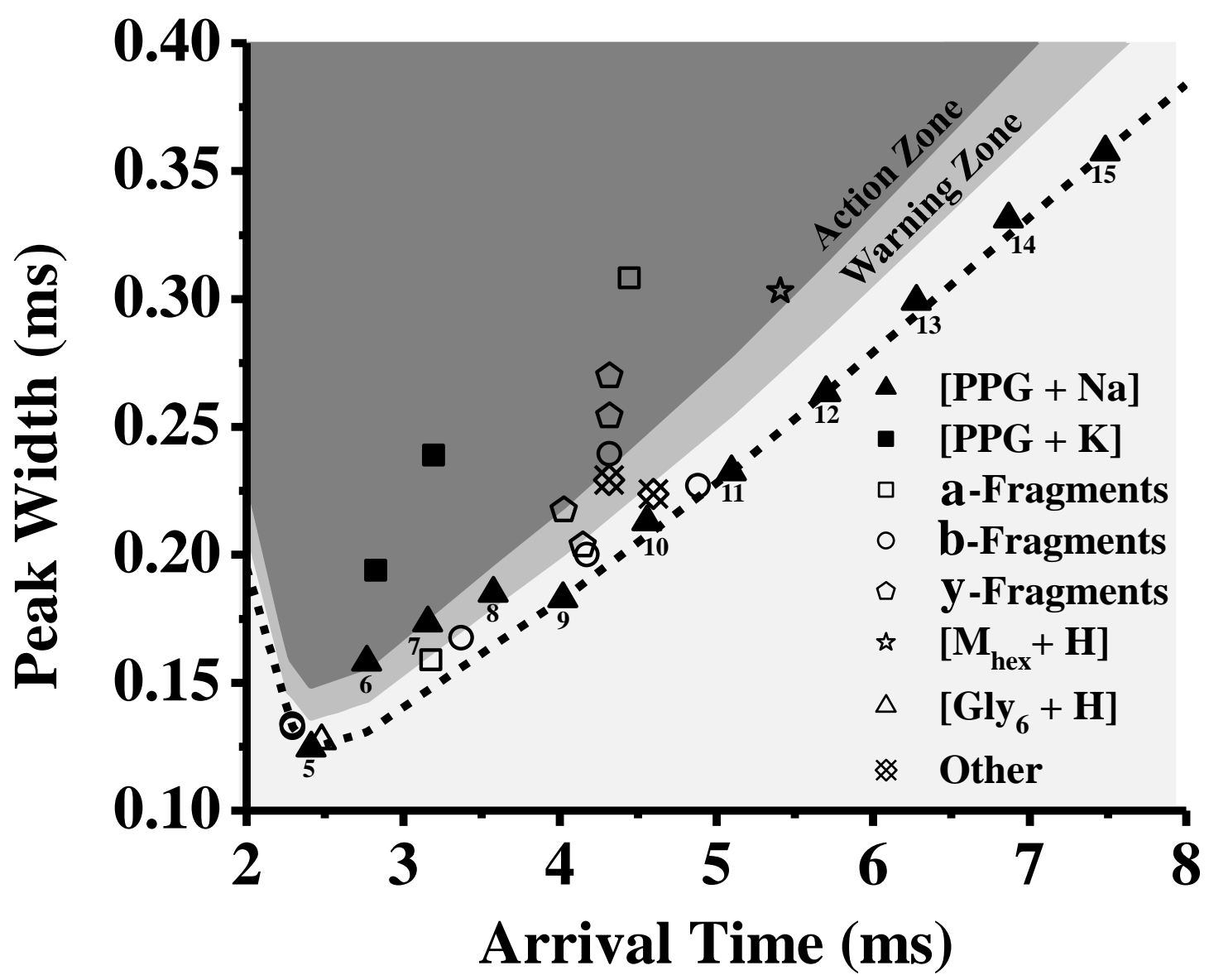

Fig 3. Plot of peak widths versus arrival time for peaks over $5 \%$ relative abundance as calculated by IM_FIT. Isotopes have been removed for simplicity but are retained in Table 1 . All ions are grouped by adduct or fragment type. "Warning Zone" and "Action Zone" correspond to IM_FIT $\mathrm{Z}$ values (see main text for detailed discussion of $\mathrm{Z}$ values) of 1 and 2, respectively. The number of PPG subunits (n) for the $\left[\mathrm{PPG}_{\mathrm{n}}+\mathrm{Na}\right]^{+}$species is numerically labeled under their respective data points. 


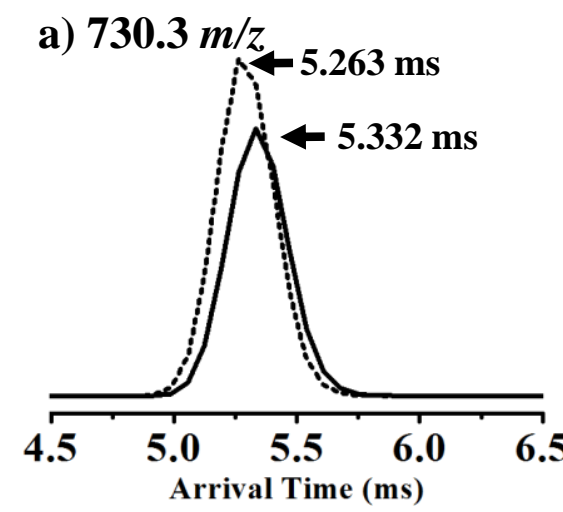

d) $600.3 \mathrm{~m} / \mathrm{z}$

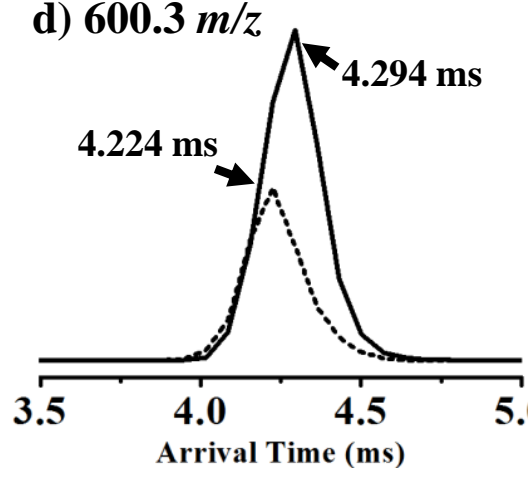

b) $598.3 \mathrm{~m} / \mathrm{z}$

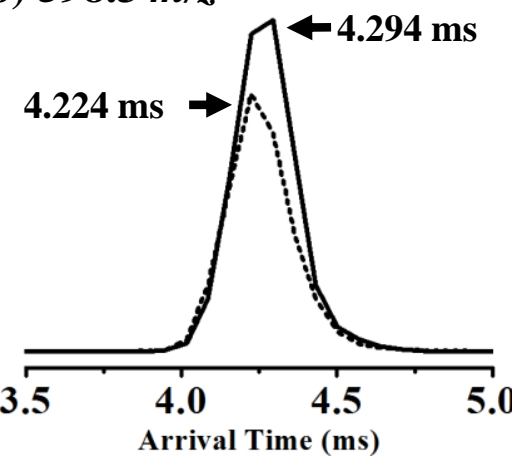

c) $599.3 \mathrm{~m} / \mathrm{z}$

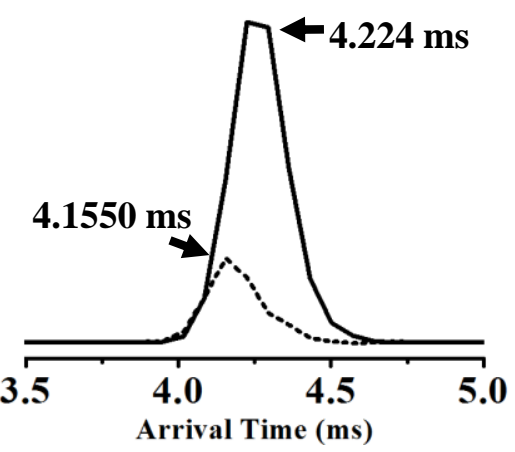

e) $542.3 \mathrm{~m} / \mathrm{z}$

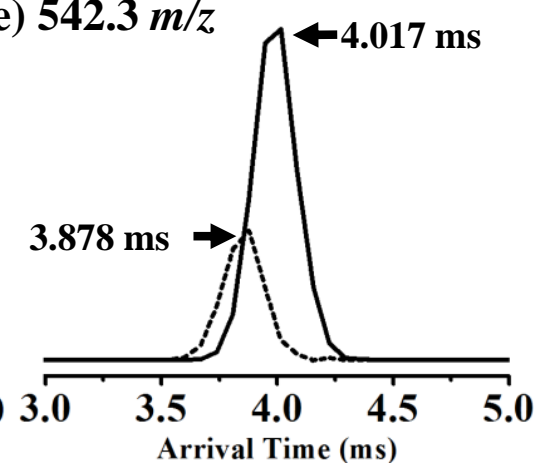

Fig 4. AIMD deconvoluted ion mobility profiles for a) $\mathrm{m} / z \mathbf{z} 730.3$ (i.e., $\left[\mathrm{M}_{\mathrm{hex}}+\mathrm{H}\right]^{+}$for both FRMYGG and MGRYGF), b) $\mathrm{m} / z 598.3$ (i.e., $\left[\mathrm{b}_{4}\right]^{+}$fragment ion generated from FRMYGG), c) $m / z 599.3$ (i.e., $\left[\mathrm{y}_{5}\right]^{+}$fragment ion generated from MGRYGF), d) $m / z 600.3$ (i.e., $\left[\mathrm{y}_{5}+\mathrm{NH}_{3}\right]^{+}$ fragment ion generated from FRMYGG), and e) $\mathrm{m} / \mathrm{z} 542.3$ (i.e., $\left[\mathrm{y}_{4}\right]^{+}$fragment ion generated from MGRYGF). Solid and dotted IM profiles are from AIMD outputs and correspond to two different deconvoluted species for $\mathrm{m} / \mathrm{z}$ values denoted in each window. 

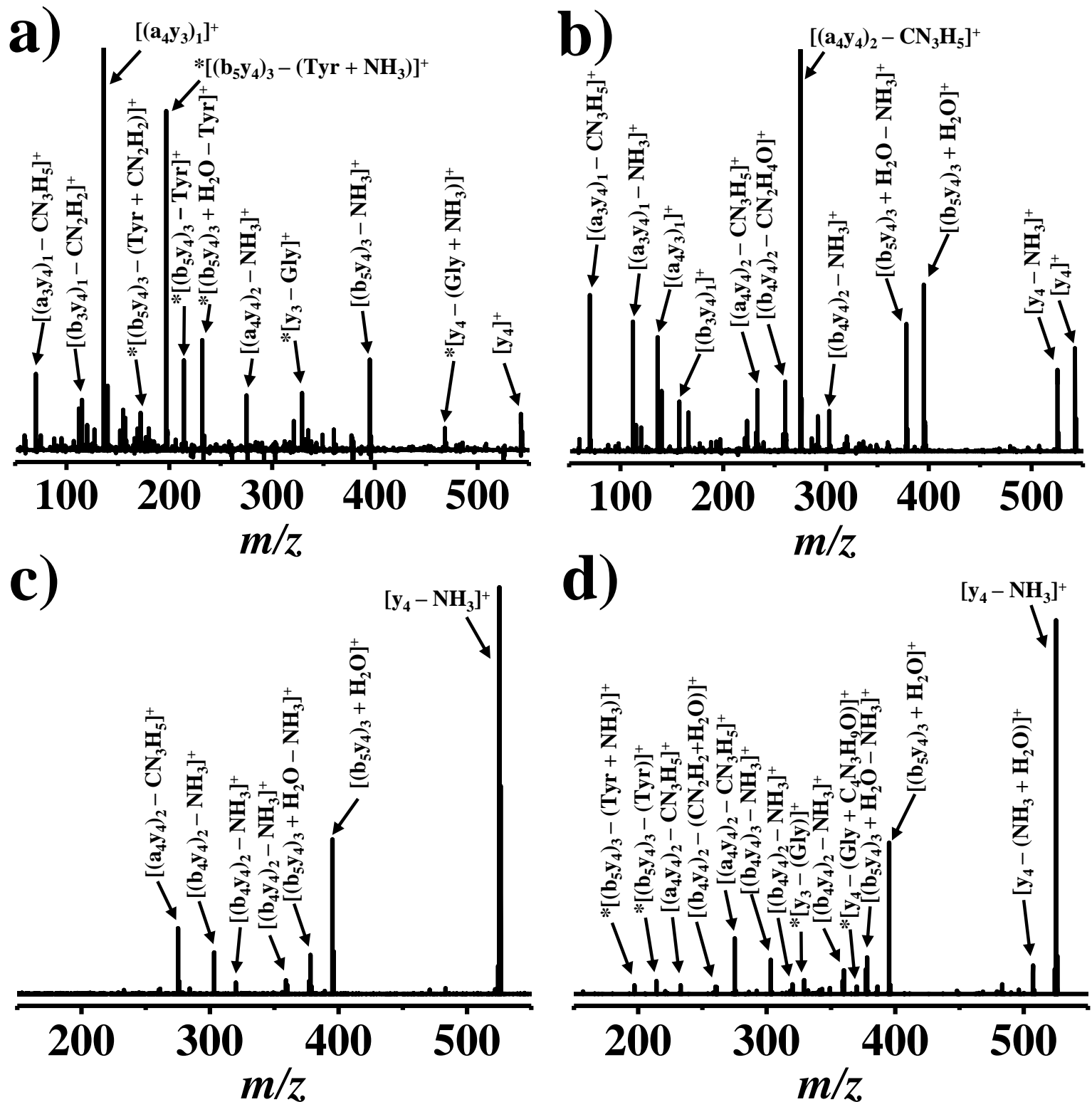

Fig 5. Reconstructed CID mass spectra after AIMD deconvolution of $\mathrm{m} / \mathrm{z} 542.3$ (measured using the Synapt G2-S) for the a) earlier arriving component and b) later arriving component. c) Orbitrap CID mass spectra from isolation of $m / z 730.3\left([\mathrm{M}+\mathrm{H}]^{+}\right.$from MGRYGF) $\rightarrow$ CID at 30 $\mathrm{V} \rightarrow$ isolation of $\mathrm{m} / \mathrm{z} 542.3\left(\left[\mathrm{y}_{4}\right]^{+}\right.$from MGRYGF $) \rightarrow$ CID at $35 \mathrm{~V}$. d) Orbitrap CID mass spectra from isolation of $\mathrm{m} / z 542.3\left(\left[\mathrm{y}_{4}\right]^{+}\right.$, generated from in-source CID of MGRYGF) $\rightarrow$ CID at $35 \mathrm{~V}$. Sequence-scrambled species are denoted by asterisks $(*)$. 


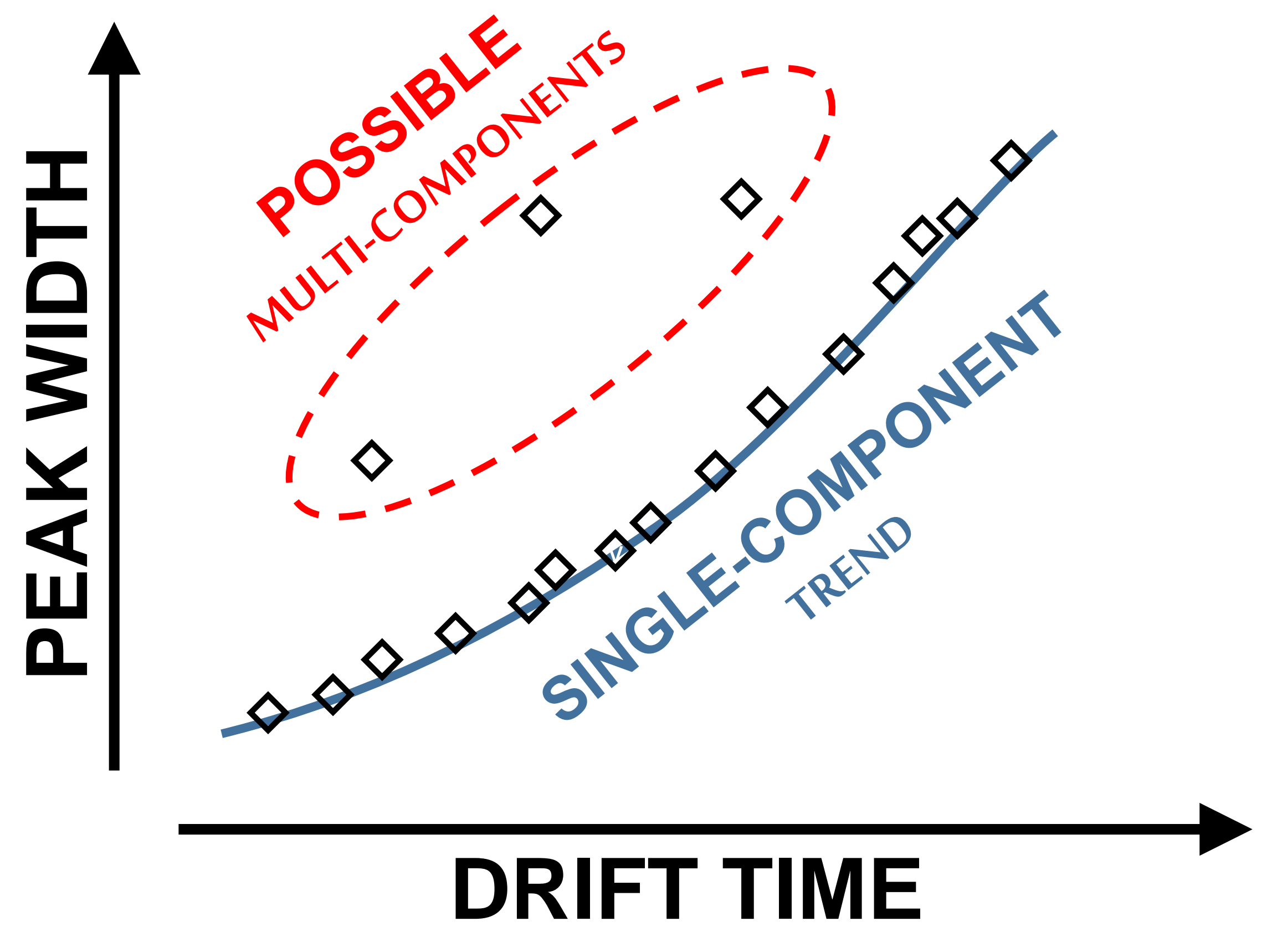

